\title{
Histomorphological Variation in the Appendicular Skeleton
}

\author{
R.A. Walker ${ }^{1, *}$, C.O. Lovejoy ${ }^{2}$ and R. Cordes ${ }^{1}$ \\ ${ }^{I}$ Department of Clinical Anatomy, New York Chiropractic College and ${ }^{2}$ Dept. of Anthropology and Division of Biomedi- \\ cal Sciences, Kent State University, USA
}

\begin{abstract}
Densities of osteons and osteon fragments at the midshafts of the femur, tibia, fibula, humerus, radius, ulna and clavicle are examined in a sample of contemporary human males and females ( $\mathrm{n}=39 ; 23$ female, 16 male), with comparative data derived from one specimen each of Gallus gallus and Felis silvestris catus. Results demonstrate that there are significant differences in mean complete and fragmentary osteon densities among bones and between the sexes. We suggest that these patterns are less a simple reflection of the so-called "Wolff's law," but instead represent not only remodeling in response to loading, but also underlying intrinsic developmental parameters specific to each bone. Given the diversity of locomotor patterns of the three species, and the resulting differences in loading environments of their limbs, this histomorphological pattern suggests that remodeling is an inherently complex phenomenon, subject to local intrinsic developmental factors in addition to mechanical loading.
\end{abstract}

Key Words: Homo sapiens, Felis silvestris catus, Gallus gallus, Wolff.

\section{INTRODUCTION}

The emergence and development of the mammalian skeleton is an exceedingly complex process, largely under genetic control, but with some influence by each bone's mechanical environment $[1,2]$. However, in recent years several aspects of that process have become significantly clarified. Among the most important is an accumulation of evidence suggesting that osteoblast behavior is highly conserved [3-5]. Despite an enormous range of body mass, actual microstrain experienced by mammalian bones has been found to fall within a very narrow range [6-11]. This raises the strong possibility that osteoblast response protocols are highly conserved, and do not vary substantially from one mammal to another. Such a view has also received strong support from studies of limb bud dynamics [4, 5]. These suggest that differences in the structure and form of the skeleton can be traced to early initial differences in the disposition of positional information (PI). Thus, morphological differences between species owe their existence almost exclusively to differences in pattern formation rather than to speciesspecific programmatic differences in the anabolic behavior of these cells (including osteoblasts). There are some obvious areas where this is probably not entirely the case, such responses to loading within epiphyseal plates. However, it is still very likely that throughout the metamorphosis of each skeletal anlagen into its adult structure, the location, speed, and composition of bone deposition depend primarily upon the inherent "programming" of osteoblasts provided by their PI, and that these protocols are very probably highly conserved among mammals. Thus, it is changes in the form and composition of anlagen and their precursive mesenchymal

*Address correspondence to this author at the Department of Clinical Anatomy, New York Chiropractic College, 2360 State Route 89, Seneca Falls, NY 13148-0800, USA; Tel: 315-568-3210; E-mail: rwalker@nycc.edu structures (as well as simultaneous alterations in the structure and composition of their soft tissue envelopes) that serve as the primary locus for skeletal evolution. These are "translated" into adult structure by conserved response protocols resident in the osteoblast and other connective tissue components. Understanding the evolutionary process, therefore, requires a thorough knowledge of the behavioral repertoire of mammalian and vertebrate osteoblasts and the nature of their systemic response systems.

A number of approaches have been taken to further refine our understanding of osteoblast behavior, including a long and varied history of observing the effects of disease processes, trauma, and clinical intervention, direct experimental manipulation of bones, systemic modeling, and behavioral observation analysis. Recently, individual cell behavior has also become a focus of study. The present contribution is an attempt to add to our knowledge of osteoblast response patterns by means of whole skeletal analysis. We do so by an intensive histological survey of the entire long bone skeletons of a normal mammal and bird, and compare these data with similar data from a sample of modern humans. We reasoned that close examination of the differences and similarities in the distribution of bone type, histological structure, and geometric properties might provide useful information about the complex behavior of bone tissue.

A number of types of adult mammalian bone have been recognized. For the most part it is lamellar, consisting of progressively deposited layers whose included blood channels do little to disturb its general arrangement. However, this type of bone only characterizes animals in which growth rate and size permit it. In mammals, in which growth rates are too rapid, plexiform or laminar bone is deposited instead [11]. In the domestic cat the size and growth rate permit the deployment of "classical" lamellar bone, and as in other species, including humans, much of this bone is later subjected 
to repair and replacement by more "modular" lamellar bone in the form of novel haversian systems. We therefore reasoned that the distribution and pattern of occurrence of these secondary systems might prove informative about the general nature of the behavior of bone tissue and its included cells.

As just noted, often in the development and maintenance of lamellar bone, factors such as repair and/or responses to novel mechanical loading require its form and/or internal composition to be altered, or remodeled. Mammalian skeletal remodeling is affected by many primary factors, including the endocrinological environment. Mechanical loading, which may vary from location to location within the skeleton and within each individual history, is an important but largely secondary determinant. For example, in individuals with paralysis or paresis from various spinal birth defects, the femur continues to grow to its normal length and to obtain virtually normal morphology. However, the quantity and quality of its cortical bone suffers. Indeed, as a consequence of differential mechanical loading, different skeletal elements within the same limb, and from side to side in contralateral members of bone pairs. While the phenomenon of skeletal remodeling has been the subject of intense scrutiny for the last several decades, intraindividual variations in the basic parameters of mammalian and vertebrate cortical bone remodeling have not been systematically investigated such that variation can be more readily understood. This research reported here addresses this basic problem.

Haversian remodeling is traditionally presumed, in part, to reflect response to mechanical forces that bone is subjected to during life [11]. Histomorphological variation within and among bones may thus reflect life history, once "background" variation attributable to other causes is understood. The standard paradigm of skeletal remodeling, often based around assumptions of the so-called "Wolff's Law," [12] portrays remodeling of skeletal elements as an adaptive response of bone tissue to the mechanical loads imposed upon it. In recent years, the validity of this assumption as the sole basis of skeletal remodeling has come into question [5, $13,14]$. To test some of these assumptions, we here examine variation within and among skeletal elements and across species, both at the tissue level and the whole bone level. Previous work has demonstrated bilateral symmetry in density of haversian structures (complete and fragmentary osteons per square millimeter in cross section) in cats [15], chickens, and the human forelimb [16]. Remodeling at the microscopic level is also correlated with remodeling and morphology at the macroscopic level [17]. Bilateral asymmetry, either at the whole bone level or at the histological level, may reflect asymmetry of loading history. We here assess bilateral symmetry at the whole bone level by examination of the cross sectional geometric properties of bones (area moments of inertia, polar moments of inertia, and cortical bone cross sectional area). We also examine differences in remodeling in different skeletal elements and between forelimbs and hindlimbs [18-21].

Density of Haversian structures, defined as complete and fragmentary secondary osteons (i.e., haversian systems) per sq. mm. of bone in cross section, are used in numerous ways by anthropologists and other investigators to assess age at death [17, 22, 23], activity levels [11, and references therein], status of health and disease $[24,25])$, and populational variation [26]. While multiple locations throughout the skeleton have been examined to assess osseous histomorphology, a systematic overview is generally lacking of the histology of the entire skeleton. Toward this end, we here examine the histomorphology of the midshafts of the major long bones of the human skeleton, and include comparisons to other vertebrates of diverse locomotor styles.

\section{METHODS}

Variation in histomorphology can occur both within a single bone and among different skeletal elements. Variation can also occur between species. Here we examine all three levels of variation.

We collected data of a number of types. We examined densities of secondary osteons and osteon fragments per sq. $\mathrm{mm}$. at the midshafts of long bones in a sample of contemporary adult human males and females $(n=39 ; 23$ female, 16 male). We also calculated densities of secondary osteons and osteon fragments in 14 pairs of human ulnae in order to quantify differences between sides in Homo sapiens. The right ulnae of these pairs are part of the larger human sample.

To examine intrabone variation, the major long bones of one specimen each of Gallus gallus (domestic chicken) and Felis silvestris catus (domestic cat) were sectioned at multiple locations along their lengths, including the midshafts. The specimen of Felis silvestris catus was a young adult female domestic shorthair. The specimen of Gallus gallus was a young adult White Leghorn male. No other information is available regarding these specimens. Additional specimens of other taxa, especially wild specimens, are desirable. These will be the subject of additional studies.

We examined the femur, tibia, humerus, radius, and ulna of all three species. The clavicle in Homo sapiens and furculum ("wishbone") in Gallus gallus were also examined. Felis silvestris catus is functionally aclaviculate (the bone is reduced to a sliver embedded in muscles cranial to the shoulder joint and has lost its connection to the rest of the skeleton [27]. One of the implications of the so-called "Wolff's law" is that bone remodels primarily in response to mechanical loads. We hypothesize that the different loading patterns necessitated by the diverse locomotor patterns of the three species included in this analysis should be apparent if this is the case.

In the specimens of Felis silvestris catus and Gallus gallus, each bone was transversely sectioned at 9 points at intervals of $10 \%$ of the bone's total length. The human bones were sectioned only at the midshaft, equivalent to the $50 \%$ segment in the bones of Felis silvestris catus and Gallus gallus. Undecalcified thin sections were made at each location. Cross-sectional properties were calculated for each section, including total and cortical area, as well as area moments of inertia and polar moment of inertia [28]. Comparisons of histomorphometric and cross sectional parameters, including complete and fragmentary secondary osteons per square millimeter (i.e., osteon and fragment density) in the section and percent of section composed of haversian bone were made between proximal and distal limb segments, between serially homologous fore and hindlimb bones, and between contra- 
lateral members of pairs of bones. Proximodistal variation within bones was also examined by collecting data at each of the 9 sections made at $10 \%$ intervals of the bones' lengths.

For human specimens, data collected include: secondary osteons per sq. mm.; fragments of secondary osteons per sq. $\mathrm{mm}$; ; and fraction of section composed of solid bone estimated via a grid system. Fraction of the section composed of solid bone gives an estimate of the area of the section that has been resorbed by osteoclastic activity. This was estimated by counting the intersects that overlaid areas of resorbed bone using an eyepiece reticule embedded with a nine-by-nine grid [29]. The percentage of intersects that take place over resorption spaces gives an estimate of the percentage of the section that has been resorbed. Subtracting this figure from 100 gives the estimate of the percent of the field composed of solid bone. Once the portion of the field composed of haversian bone is known, the density of osteons and osteon fragments per square millimeter in that fraction of bone can be calculated. Derived data thus include the number of secondary osteons and osteon fragments per square millimeter normalized by percent of field composed of solid haversian bone. For the 14 pairs of left and right human ulnae, total and cortical area, area moments of inertia, and polar moments of inertia were also calculated for comparison with similar data from Felis silvestris catus and Gallus gallus.

\section{RESULTS}

Comparisons can be made among species, among bones within species, between fore and hindlimbs, between sides, and within individual bones, at both microscopic and macroscopic levels. Both birds and mammals exhibit haversian remodeling within cortical bone [30]. Therefore, remodeling at the microscopic level in both these taxa can be compared directly with that of humans. Since all three species have a dramatically different locomotor style, under the assumptions of the so-called "Wolff's law" we would expect that differential loading of the appendicular skeleton would manifest in histomorphology and/or gross morphology. Presence or absence of these differences can aid in interpreting the role of differential loading in determining macroscopic and microscopic cortical bone morphology.

\section{Intrabone Variation: Comparative Histomorphology}

In Felis silvestris catus, the amount of haversian (i.e., remodeled) bone varies substantially from one section to another, and from one long bone to another. A definite trend emerges from an examination of the entire feline skeleton with respect to the diaphyseal distribution of secondary haversian systems. There is a clear proximodistal reduction in the number of complete and fragmentary secondary osteons within each individual long bone, with the exception of the humerus, where the trend is less obvious (Table 1). The limb bones of Gallus gallus show a somewhat different pattern, wherein the midshaft regions of the bones show a greater amount of remodeling and osteoblastic activity, while the proximal and distal portions of the bones are generally more quiescent (Table 2). All bones examined, with the exception of the furculum, were composed of haversian bone. The chicken and cat were both young adult specimens. Some osteon fragments were observed in Felis silvestris catus, though they were very infrequent. Additionally, osteons in Felis silvestris catus were considerably larger than those in Gallus gallus. As a result, the osteons denisities are considerably higher in Gallus gallus than in either Felis silvestris catus or in Homo sapiens. The furculum in the specimen of Gallus gallus examined here was quiescent and unremodeled.

Within the skeleton of Felis silvestris catus, there are regional differences in the distribution of haversian structures. In the femur, there is a dense concentration of osteons located posterolaterally, in the region of the linea aspera. In the tibia, the same patterns emerge as in the femur, but there are concentrations of osteons associated with the three corners of its essentially triangular cross section. The feline tibia has dense concentrations of osteons and substantial amounts of haversian bone anteriorly, which become progressively less dense in the distal-most few segments, while other regions of the tibia appear more variable. The anterior concentration of osteons and amount of haversian bone in the tibia corresponds to its sharp anterior border. The feline humerus, radius, and ulna also show concentrations of osteons at sharp borders, for example, at the interosseous crests and supracondylar ridges. These are areas of concentrations of Sharpey's fibers which likely influence remodeling rates, because entheses are known to be under specific local control.

In marked distinction to Felis silvestris catus, Gallus gallus demonstrates a much more general distribution of osteons throughout the cortex, while at the same time showing a much higher concentration of vascular channels. As noted above, the individual haversian systems in Gallus gallus are smaller than those in Felis silvestris catus or in Homo sapiens. The limb bones of Gallus gallus, by contrast to $\mathrm{Fe}$ lis silvestris catus or Homo sapiens, are generally round to oval in cross section and do not demonstrate sharp interosseous borders. Likewise, they do not demonstrate the localized concentrations of secondary osteons seen in Felis silvestris catus. We suggest that sites of muscle attachment, and therefore the distribution of Sharpey's fibers, may be more diffuse and or more periosteal in Gallus gallus.

The bones of the antebrachium show greater remodeling activity than the brachium or the bones of the hindlimb, as evinced by densities of complete and fragmentary osteons. In Felis silvestris catus, the right antebrachium demonstrates higher numbers of haversian structures per square millimeter than the left (Fig. 1). In both Felis silvestris catus and Gallus gallus, the forelimb has a higher density of haversian structures than the hindlimb, and the radius and ulna more than the humerus, but there is no left-right asymmetry in the forelimb of Gallus gallus, nor in the hindlimbs of either species (Table 1). In Homo sapiens there is no significant difference in density of haversian structures between forelimb and hindlimb, and, as will be discussed below, no evidence of bilateral asymmetry (see Table 4 ).

There are similar patterns of remodeling between Gallus gallus and Felis silvestris catus (Tables 1 and 2). While Gallus gallus has two to three times the density of channels for blood vessels as a comparable section in Felis silvestris catus, both exhibit a very similar pattern; that is, in both taxa and in all bones examined, the highest densities of structures are near midshaft. Further, in both Gallus gallus and Felis silvestris catus, higher densities are found in the forelimb 
Table 1. Densities of Osteons and Fragments, Bilaterally Compared, by Species. (a) Osteons per sq. mm. (b) Osteon Fragments per sq. mm.

(a) Osteons per sq. mm.

\section{SPECIES Felis silvestris catus}

\begin{tabular}{|c|c|c|c|c|c|c|c|c|c|c|}
\hline \multirow{2}{*}{$\begin{array}{c}\text { Distance from } \\
\text { Proximal End of Bone }\end{array}$} & \multicolumn{10}{|c|}{ BONE } \\
\hline & $\begin{array}{l}\text { Left } \\
\text { Femur }\end{array}$ & $\begin{array}{c}\text { Left } \\
\text { Tibia }\end{array}$ & $\begin{array}{c}\text { Left } \\
\text { Humerus }\end{array}$ & $\begin{array}{c}\text { Left } \\
\text { Radius }\end{array}$ & $\begin{array}{l}\text { Left } \\
\text { Ulna }\end{array}$ & $\begin{array}{l}\text { Right } \\
\text { Femur }\end{array}$ & $\begin{array}{l}\text { Right } \\
\text { Tibia }\end{array}$ & $\begin{array}{c}\text { Right } \\
\text { Humerus }\end{array}$ & $\begin{array}{l}\text { Right } \\
\text { Radius }\end{array}$ & $\begin{array}{c}\text { Right } \\
\text { Ulna }\end{array}$ \\
\hline $10 \%$ & 3.9 & 5.2 & 3.8 & 11.1 & 6.9 & 5.6 & 4.7 & 3.5 & 18.1 & 19.8 \\
\hline $20 \%$ & 9.9 & 7.6 & 3.4 & 11.4 & 16.9 & 10.8 & 7.2 & 4.7 & 20.8 & 29.0 \\
\hline $50 \%$ & 8.0 & 12.6 & 6.6 & 14.5 & 11.4 & 4.3 & 16.9 & 14.1 & 16.8 & 15.5 \\
\hline $60 \%$ & 10.6 & 7.9 & 5.0 & 8.6 & 13.9 & 10.2 & 12.7 & 8.0 & 13.3 & 13.0 \\
\hline $70 \%$ & 6.3 & 11.8 & 2.9 & 6.2 & 11.2 & 7.8 & 13.2 & 6.5 & 10.1 & 7.8 \\
\hline $80 \%$ & 3.8 & 6.3 & 4.0 & 4.5 & 3.8 & 5.7 & 6.6 & 4.3 & 5.2 & 5.9 \\
\hline
\end{tabular}

\section{SPECIES Gallus gallus}

\begin{tabular}{|c|c|c|c|c|c|c|c|c|c|c|}
\hline \multirow{2}{*}{$\begin{array}{c}\text { Distance from } \\
\text { Proximal End of Bone }\end{array}$} & \multicolumn{10}{|c|}{ BONE } \\
\hline & $\begin{array}{c}\text { Left } \\
\text { Femur }\end{array}$ & $\begin{array}{c}\text { Left } \\
\text { Tibia }\end{array}$ & $\begin{array}{c}\text { Left } \\
\text { Humerus }\end{array}$ & $\begin{array}{c}\text { Left } \\
\text { Radius }\end{array}$ & $\begin{array}{l}\text { Left } \\
\text { Ulna }\end{array}$ & $\begin{array}{l}\text { Right } \\
\text { Femur }\end{array}$ & $\begin{array}{l}\text { Right } \\
\text { Tibia }\end{array}$ & $\begin{array}{c}\text { Right } \\
\text { Humerus }\end{array}$ & $\begin{array}{l}\text { Right } \\
\text { Radius }\end{array}$ & $\begin{array}{c}\text { Right } \\
\text { Ulna }\end{array}$ \\
\hline $10 \%$ & .0 & 1.6 & 1.7 & .3 & 7.9 & .0 & .0 & 7.2 & 1.0 & 6.6 \\
\hline $20 \%$ & 4.3 & 8.5 & 8.5 & 2.1 & 31.2 & 2.3 & 6.2 & 15.4 & 5.6 & 21.7 \\
\hline $50 \%$ & 18.9 & 29.0 & 62.2 & 83.3 & 75.4 & 17.0 & 27.0 & 81.2 & 66.2 & 80.0 \\
\hline $60 \%$ & 22.9 & 37.2 & 58.6 & 55.2 & 84.9 & 26.0 & 37.8 & 40.4 & 65.9 & 91.0 \\
\hline $70 \%$ & 20.5 & 55.7 & 12.9 & 43.0 & 29.7 & 23.6 & 37.3 & 13.8 & 47.5 & 63.5 \\
\hline $80 \%$ & 16.4 & 14.9 & 13.5 & 17.9 & 5.9 & 8.6 & 11.4 & 18.9 & 42.4 & 14.6 \\
\hline
\end{tabular}

(b) Osteon Fragments per sq. mm.

SPECIES Felis silvestris catus

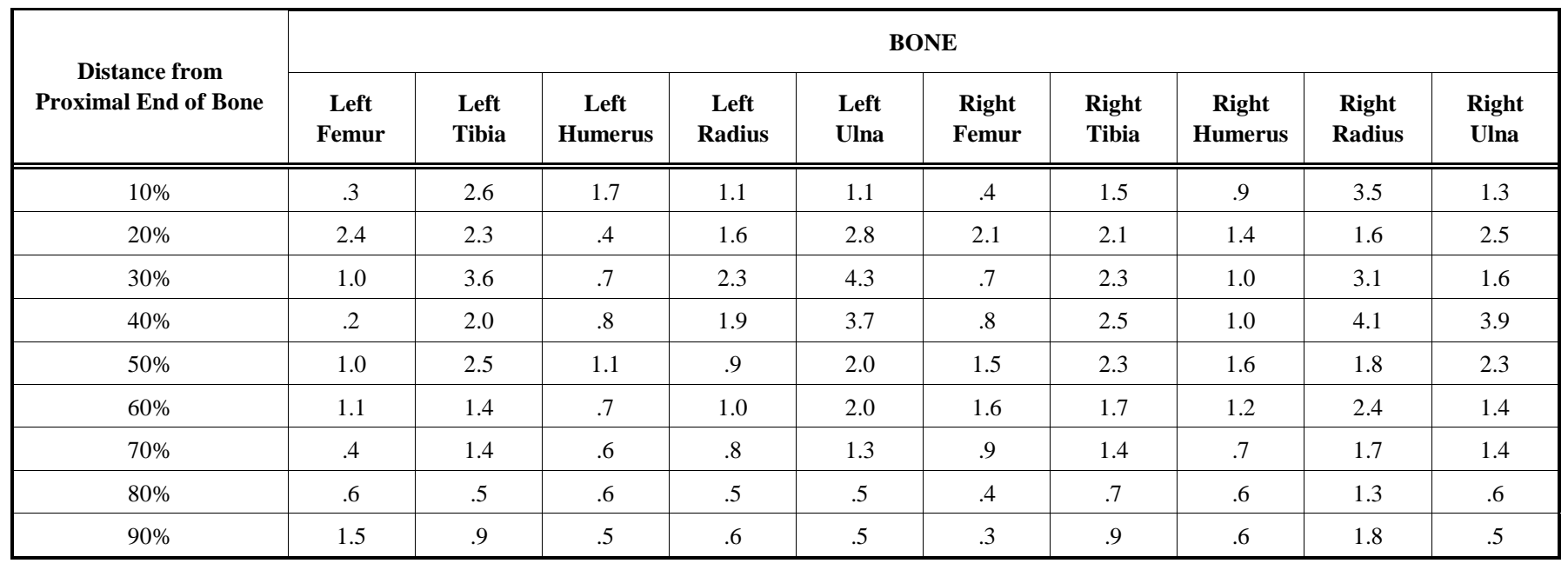


Table 2. Normalized Anteroposterior Area Moment of Inertia ( $\mathbf{N I}_{\mathrm{ap}}$, Normalized Mediolateral Area Moment of $\mathbf{I n e r t i a}\left(\mathbf{N I}_{\mathrm{ml}}\right)$, Normalized Polar Moment of Inertia (NJ), and Normalized Cortical Area (NCA), by Side and by Species. (a) $\mathrm{NI}_{\text {ap }}$, in Felis silvestris catus. (b) $\mathrm{NI}_{\mathrm{ap}}$, in Gallus gallus. (c) $\mathrm{NI}_{\mathrm{ml}}$, in Felis silvestris catus. (d) $\mathrm{NI}_{\mathrm{ml}}$, in Gallus gallus. (e) $\mathrm{NJ}$ in Felis silvestris catus. (f) NJ in Gallus gallus. (g) NCA in Felis silvestris catus. (h) NCA in Gallus gallus

(a) $\mathrm{NI}_{\mathrm{ap}}$, in Felis silvestris catus

\begin{tabular}{|c|c|c|c|c|c|c|c|c|c|c|}
\hline \multirow{2}{*}{$\begin{array}{l}\text { Distance from } \\
\text { Proximal End of Bone }\end{array}$} & \multicolumn{10}{|c|}{ BONE } \\
\hline & $\begin{array}{c}\text { Left } \\
\text { Femur }\end{array}$ & $\begin{array}{c}\text { Left } \\
\text { Tibia }\end{array}$ & $\begin{array}{c}\text { Left } \\
\text { Humerus }\end{array}$ & $\begin{array}{c}\text { Left } \\
\text { Radius }\end{array}$ & $\begin{array}{l}\text { Left } \\
\text { Ulna }\end{array}$ & $\begin{array}{l}\text { Right } \\
\text { Femur }\end{array}$ & $\begin{array}{l}\text { Right } \\
\text { Tibia }\end{array}$ & $\begin{array}{c}\text { Right } \\
\text { Humerus }\end{array}$ & $\begin{array}{c}\text { Right } \\
\text { Radius }\end{array}$ & $\begin{array}{l}\text { Right } \\
\text { Ulna }\end{array}$ \\
\hline $10 \%$ & 4.37 & 5.11 & 5.64 & .23 & .88 & 3.85 & 5.60 & 4.31 & .16 & 1.99 \\
\hline $20 \%$ & 1.82 & 3.28 & 3.05 & .09 & 1.28 & 1.26 & 2.52 & 3.58 & .07 & 1.30 \\
\hline $50 \%$ & .95 & 1.18 & 1.41 & .09 & .29 & .86 & .91 & 1.17 & .07 & .22 \\
\hline $60 \%$ & .97 & .97 & .96 & .11 & .12 & .97 & .69 & .90 & .08 & .16 \\
\hline $70 \%$ & 1.05 & .72 & .95 & .13 & .14 & .88 & .67 & .81 & .09 & .17 \\
\hline $80 \%$ & 1.81 & .74 & 1.26 & .12 & .12 & 1.08 & .67 & 1.10 & .10 & .10 \\
\hline
\end{tabular}

(b) $\mathrm{NI}_{\mathrm{ap}}$, in Gallus gallus

\begin{tabular}{|c|c|c|c|c|c|c|c|c|c|c|}
\hline \multirow{2}{*}{$\begin{array}{c}\text { Distance from } \\
\text { Proximal End of Bone }\end{array}$} & \multicolumn{10}{|c|}{ BONE } \\
\hline & $\begin{array}{c}\text { Left } \\
\text { Femur }\end{array}$ & $\begin{array}{l}\text { Left } \\
\text { Tibia }\end{array}$ & $\begin{array}{c}\text { Left } \\
\text { Humerus }\end{array}$ & $\begin{array}{c}\text { Left } \\
\text { Radius }\end{array}$ & $\begin{array}{l}\text { Left } \\
\text { Ulna }\end{array}$ & $\begin{array}{l}\text { Right } \\
\text { Femur }\end{array}$ & $\begin{array}{l}\text { Right } \\
\text { Tibia }\end{array}$ & $\begin{array}{c}\text { Right } \\
\text { Humerus }\end{array}$ & $\begin{array}{l}\text { Right } \\
\text { Radius }\end{array}$ & $\begin{array}{l}\text { Right } \\
\text { Ulna }\end{array}$ \\
\hline $10 \%$ & 6.60 & 3.37 & 3.17 & .28 & 1.46 & 6.51 & 5.14 & 2.01 & .31 & 2.02 \\
\hline $20 \%$ & 3.06 & 2.56 & 4.11 & .19 & .92 & 5.33 & 4.10 & 4.74 & .31 & 2.18 \\
\hline $30 \%$ & 4.61 & 3.36 & 1.84 & .09 & .69 & 2.61 & 3.23 & 2.14 & .17 & 2.02 \\
\hline $40 \%$ & 2.20 & 3.14 & 1.24 & .07 & .69 & 2.26 & 1.72 & 1.21 & .15 & 1.21 \\
\hline $50 \%$ & 2.82 & 2.47 & 1.24 & .08 & .84 & 2.77 & 2.15 & 1.12 & .10 & .51 \\
\hline $60 \%$ & 3.73 & 2.22 & .87 & .09 & .78 & 3.64 & 1.71 & 1.81 & .11 & .49 \\
\hline $70 \%$ & 3.85 & 1.91 & 1.32 & .15 & .84 & 4.18 & 2.24 & 1.51 & .11 & .37 \\
\hline $80 \%$ & 3.51 & 2.64 & 1.62 & .12 & 1.19 & 3.82 & 2.16 & 1.86 & .14 & .80 \\
\hline $90 \%$ & 4.49 & 2.68 & .81 & .22 & 1.84 & 3.97 & 3.81 & .61 & .26 & .86 \\
\hline
\end{tabular}

(c) $\mathrm{NI}_{\mathrm{ml}}$, in Felis silvestris catus

\begin{tabular}{|c|c|c|c|c|c|c|c|c|c|c|}
\hline \multirow{2}{*}{$\begin{array}{c}\text { Distance from } \\
\text { Proximal End of Bone }\end{array}$} & \multicolumn{10}{|c|}{ BONE } \\
\hline & $\begin{array}{c}\text { Left } \\
\text { Femur }\end{array}$ & $\begin{array}{c}\text { Left } \\
\text { Tibia }\end{array}$ & $\begin{array}{c}\text { Left } \\
\text { Humerus }\end{array}$ & $\begin{array}{c}\text { Left } \\
\text { Radius }\end{array}$ & $\begin{array}{l}\text { Left } \\
\text { Ulna }\end{array}$ & $\begin{array}{l}\text { Right } \\
\text { Femur }\end{array}$ & $\begin{array}{l}\text { Right } \\
\text { Tibia }\end{array}$ & $\begin{array}{c}\text { Right } \\
\text { Humerus }\end{array}$ & $\begin{array}{l}\text { Right } \\
\text { Radius }\end{array}$ & $\begin{array}{l}\text { Right } \\
\text { Ulna }\end{array}$ \\
\hline $10 \%$ & 2.95 & 3.45 & 2.70 & .28 & .29 & 2.11 & 2.98 & 2.37 & .24 & .23 \\
\hline $20 \%$ & 1.87 & 2.04 & 2.52 & .20 & .23 & 1.35 & 1.67 & 2.12 & .14 & .27 \\
\hline $30 \%$ & 1.15 & 1.08 & 1.54 & .35 & .09 & 1.12 & .90 & 2.02 & .16 & .06 \\
\hline $40 \%$ & 1.14 & .80 & 1.18 & .26 & .17 & 1.26 & .78 & 1.07 & .22 & .15 \\
\hline $50 \%$ & 1.03 & .69 & .83 & .24 & .17 & 1.15 & .56 & .87 & .23 & .12 \\
\hline $60 \%$ & 1.20 & .92 & .68 & .27 & .03 & 1.27 & .85 & .76 & .24 & .11 \\
\hline $70 \%$ & 1.31 & .56 & .97 & .31 & .15 & 1.24 & .61 & .89 & .19 & .16 \\
\hline $80 \%$ & 2.31 & 1.15 & 3.33 & .28 & .19 & 1.28 & .86 & 2.33 & .22 & .16 \\
\hline $90 \%$ & 4.55 & 1.54 & 10.77 & .56 & .09 & 3.25 & 1.39 & .97 & .55 & .07 \\
\hline
\end{tabular}


(d) $\mathrm{NI}_{\mathrm{ml}}$, in Gallus gallus

\begin{tabular}{|c|c|c|c|c|c|c|c|c|c|c|}
\hline \multirow{2}{*}{$\begin{array}{c}\text { Distance from } \\
\text { Proximal End of Bone }\end{array}$} & \multicolumn{10}{|c|}{ BONE } \\
\hline & $\begin{array}{c}\text { Left } \\
\text { Femur }\end{array}$ & $\begin{array}{c}\text { Left } \\
\text { Tibia }\end{array}$ & $\begin{array}{c}\text { Left } \\
\text { Humerus }\end{array}$ & $\begin{array}{c}\text { Left } \\
\text { Radius }\end{array}$ & $\begin{array}{l}\text { Left } \\
\text { Ulna }\end{array}$ & $\begin{array}{l}\text { Right } \\
\text { Femur }\end{array}$ & $\begin{array}{l}\text { Right } \\
\text { Tibia }\end{array}$ & $\begin{array}{c}\text { Right } \\
\text { humerus }\end{array}$ & $\begin{array}{l}\text { Right } \\
\text { Radius }\end{array}$ & $\begin{array}{c}\text { Right } \\
\text { Ulna }\end{array}$ \\
\hline $10 \%$ & 11.82 & 6.40 & 11.87 & .50 & 3.14 & 14.98 & 2.93 & 11.57 & .39 & 1.83 \\
\hline $20 \%$ & 1.83 & 3.22 & 11.68 & .28 & 2.02 & 3.11 & 2.86 & 11.27 & .30 & 1.70 \\
\hline $40 \%$ & 3.41 & 1.86 & 2.34 & .09 & 1.37 & 2.24 & 1.99 & 1.94 & .12 & 1.53 \\
\hline $50 \%$ & 3.33 & 1.42 & 1.66 & .11 & .52 & 2.41 & 2.25 & 1.79 & .10 & 1.04 \\
\hline $60 \%$ & 4.21 & 2.32 & 1.19 & .12 & .52 & 4.09 & 2.50 & 2.00 & .11 & .78 \\
\hline $70 \%$ & 4.45 & 2.81 & 2.06 & .20 & .60 & 5.04 & 3.54 & 1.89 & .13 & .54 \\
\hline $80 \%$ & 4.20 & 3.74 & 4.27 & .24 & .69 & 6.67 & 4.13 & 3.90 & .11 & 1.04 \\
\hline
\end{tabular}

(e) NJ in Felis silvestris catus

\begin{tabular}{|c|c|c|c|c|c|c|c|c|c|c|}
\hline \multirow{2}{*}{$\begin{array}{c}\text { Distance from } \\
\text { Proximal End of Bone }\end{array}$} & \multicolumn{10}{|c|}{ BONE } \\
\hline & $\begin{array}{c}\text { Left } \\
\text { Femur }\end{array}$ & $\begin{array}{l}\text { Left } \\
\text { Tibia }\end{array}$ & $\begin{array}{c}\text { Left } \\
\text { Humerus }\end{array}$ & $\begin{array}{c}\text { Left } \\
\text { Radius }\end{array}$ & $\begin{array}{l}\text { Left } \\
\text { Ulna }\end{array}$ & $\begin{array}{l}\text { Right } \\
\text { Femur }\end{array}$ & $\begin{array}{l}\text { Right } \\
\text { Tibia }\end{array}$ & $\begin{array}{c}\text { Right } \\
\text { Humerus }\end{array}$ & $\begin{array}{l}\text { Right } \\
\text { Radius }\end{array}$ & $\begin{array}{l}\text { Right } \\
\text { Ulna }\end{array}$ \\
\hline $10 \%$ & 7.32 & 8.57 & 8.34 & .50 & 1.17 & 5.96 & 8.59 & 6.68 & .40 & 2.22 \\
\hline $20 \%$ & 3.69 & 5.32 & 5.58 & .29 & 1.50 & 2.61 & 4.19 & 5.70 & .21 & 1.57 \\
\hline $30 \%$ & 2.28 & 2.63 & 4.05 & .46 & .69 & 2.06 & 2.27 & 4.65 & .22 & .62 \\
\hline $40 \%$ & 2.19 & 2.11 & 2.97 & .35 & .55 & 2.42 & 1.84 & 2.65 & .30 & .54 \\
\hline $50 \%$ & 1.98 & 1.87 & 2.24 & .33 & .46 & 2.01 & 1.47 & 2.03 & .30 & .34 \\
\hline $60 \%$ & 2.16 & 1.89 & 1.64 & .38 & .15 & 2.23 & 1.54 & 1.66 & .32 & .28 \\
\hline $70 \%$ & 2.36 & 1.27 & 1.92 & .43 & .29 & 2.12 & 1.27 & 1.70 & .28 & .32 \\
\hline $80 \%$ & 4.12 & 1.88 & 4.59 & .40 & .31 & 2.36 & 1.53 & 3.42 & .31 & .26 \\
\hline $90 \%$ & 8.07 & 2.51 & 12.96 & .76 & .25 & 5.50 & 2.58 & 2.72 & .80 & .22 \\
\hline
\end{tabular}

(f) NJ in Gallus gallus

\begin{tabular}{|c|c|c|c|c|c|c|c|c|c|c|}
\hline \multirow{2}{*}{$\begin{array}{l}\text { Distance from Proximal } \\
\text { End of Bone }\end{array}$} & \multicolumn{10}{|c|}{ BONE } \\
\hline & $\begin{array}{c}\text { Left } \\
\text { Femur }\end{array}$ & $\begin{array}{l}\text { Left } \\
\text { Tibia }\end{array}$ & $\begin{array}{c}\text { Left } \\
\text { Humerus }\end{array}$ & $\begin{array}{c}\text { Left } \\
\text { Radius }\end{array}$ & $\begin{array}{l}\text { Left } \\
\text { Ulna }\end{array}$ & $\begin{array}{l}\text { Right } \\
\text { Femur }\end{array}$ & $\begin{array}{l}\text { Right } \\
\text { Tibia }\end{array}$ & $\begin{array}{c}\text { Right } \\
\text { Humerus }\end{array}$ & $\begin{array}{l}\text { Right } \\
\text { Radius }\end{array}$ & $\begin{array}{l}\text { Right } \\
\text { Ulna }\end{array}$ \\
\hline $10 \%$ & 18.42 & 9.76 & 15.04 & .78 & 4.61 & 21.49 & 8.07 & 13.58 & .71 & 3.85 \\
\hline $20 \%$ & 4.89 & 5.78 & 15.79 & .47 & 2.94 & 8.44 & 6.96 & 16.01 & .61 & 3.88 \\
\hline $30 \%$ & 7.56 & 5.96 & 5.56 & .23 & 1.81 & 5.03 & 6.37 & 5.52 & .34 & 3.83 \\
\hline $40 \%$ & 5.61 & 5.00 & 3.57 & .16 & 2.06 & 4.49 & 3.71 & 3.15 & .28 & 2.74 \\
\hline $50 \%$ & 6.16 & 3.88 & 2.90 & .19 & 1.36 & 5.18 & 4.40 & 2.91 & .20 & 1.54 \\
\hline $60 \%$ & 7.93 & 4.54 & 2.06 & .22 & 1.29 & 7.73 & 4.22 & 3.81 & .22 & 1.27 \\
\hline $70 \%$ & 8.30 & 4.72 & 3.38 & .35 & 1.44 & 9.21 & 5.78 & 3.40 & .24 & .91 \\
\hline $80 \%$ & 7.70 & 6.38 & 5.89 & .36 & 1.88 & 10.48 & 6.29 & 5.76 & .25 & 1.84 \\
\hline $90 \%$ & 12.06 & 6.82 & 4.72 & .65 & 3.38 & 9.40 & 11.02 & 4.19 & .46 & 2.10 \\
\hline
\end{tabular}


(Table 2) contd....

(g) NCA in Felis silvestris catus

\begin{tabular}{|c|c|c|c|c|c|c|c|c|c|c|}
\hline $\begin{array}{c}\text { Distance from } \\
\text { Proximal End of Bone }\end{array}$ & $\begin{array}{l}\text { Left } \\
\text { Femur }\end{array}$ & $\begin{array}{c}\text { Left } \\
\text { Tibia }\end{array}$ & $\begin{array}{c}\text { Left } \\
\text { Humerus }\end{array}$ & $\begin{array}{c}\text { Left } \\
\text { Radius }\end{array}$ & $\begin{array}{l}\text { Left } \\
\text { Ulna }\end{array}$ & $\begin{array}{l}\text { Right } \\
\text { Femur }\end{array}$ & $\begin{array}{l}\text { Right } \\
\text { Tibia }\end{array}$ & $\begin{array}{c}\text { Right } \\
\text { Humerus }\end{array}$ & $\begin{array}{l}\text { Right } \\
\text { Radius }\end{array}$ & $\begin{array}{l}\text { Right } \\
\text { Ulna }\end{array}$ \\
\hline $10 \%$ & 4.25 & 3.56 & 3.38 & 1.74 & 1.54 & 2.44 & 2.69 & 2.80 & 1.26 & 1.06 \\
\hline $20 \%$ & 2.79 & 3.19 & 3.34 & 1.36 & 1.95 & 2.12 & 2.46 & 2.70 & 1.13 & 2.01 \\
\hline $40 \%$ & 2.47 & 2.24 & 3.11 & 1.37 & 1.35 & 2.24 & 2.10 & 2.65 & 1.21 & 1.26 \\
\hline $50 \%$ & 2.17 & 2.35 & 3.13 & 1.37 & 1.30 & 2.09 & 2.05 & 2.42 & 1.18 & 1.06 \\
\hline $60 \%$ & 2.29 & 2.46 & 2.54 & 1.44 & .78 & 2.05 & 2.13 & 2.27 & 1.22 & .95 \\
\hline $70 \%$ & 2.52 & 1.93 & 3.15 & 1.50 & 1.05 & 2.16 & 1.77 & 2.37 & 1.25 & 1.06 \\
\hline $80 \%$ & 3.53 & 2.20 & 4.05 & 1.44 & 1.11 & 2.05 & 1.92 & 3.41 & 1.19 & .95 \\
\hline
\end{tabular}

(h) NCA in Gallus gallus

\begin{tabular}{|c|c|c|c|c|c|c|c|c|c|c|}
\hline \multirow{2}{*}{$\begin{array}{c}\text { Distance from } \\
\text { Proximal End of Bone }\end{array}$} & \multicolumn{10}{|c|}{ BONE } \\
\hline & $\begin{array}{l}\text { Left } \\
\text { Femur }\end{array}$ & $\begin{array}{l}\text { Left } \\
\text { Tibia }\end{array}$ & $\begin{array}{c}\text { Left } \\
\text { Humerus }\end{array}$ & $\begin{array}{c}\text { Left } \\
\text { Radius }\end{array}$ & Left Ulna & $\begin{array}{l}\text { Right } \\
\text { Femur }\end{array}$ & $\begin{array}{l}\text { Right } \\
\text { Tibia }\end{array}$ & $\begin{array}{c}\text { Right } \\
\text { Humerus }\end{array}$ & $\begin{array}{l}\text { Right } \\
\text { Radius }\end{array}$ & $\begin{array}{l}\text { Right } \\
\text { Ulna }\end{array}$ \\
\hline $10 \%$ & 7.14 & 1.68 & 6.74 & 2.91 & 4.20 & 6.96 & 1.61 & 5.50 & 2.29 & 4.22 \\
\hline $20 \%$ & 3.30 & 2.24 & 10.01 & 2.35 & 4.09 & 4.64 & 3.94 & 8.88 & 2.29 & 4.43 \\
\hline $40 \%$ & 4.86 & 3.74 & 5.19 & 1.45 & 3.77 & 4.11 & 2.93 & 4.28 & 1.68 & 4.78 \\
\hline $50 \%$ & 6.33 & 3.50 & 5.00 & 1.69 & 3.41 & 5.16 & 4.24 & 4.82 & 1.70 & 3.53 \\
\hline $60 \%$ & 7.18 & 4.18 & 4.01 & 1.90 & 3.02 & 6.35 & 3.91 & 5.65 & 1.76 & 3.05 \\
\hline $70 \%$ & 6.00 & 3.53 & 3.95 & 2.29 & 3.02 & 5.56 & 4.01 & 4.51 & 1.70 & 2.14 \\
\hline $80 \%$ & 5.04 & 3.00 & 6.09 & 2.21 & 3.22 & 6.10 & 3.16 & 5.53 & 1.71 & 2.99 \\
\hline
\end{tabular}

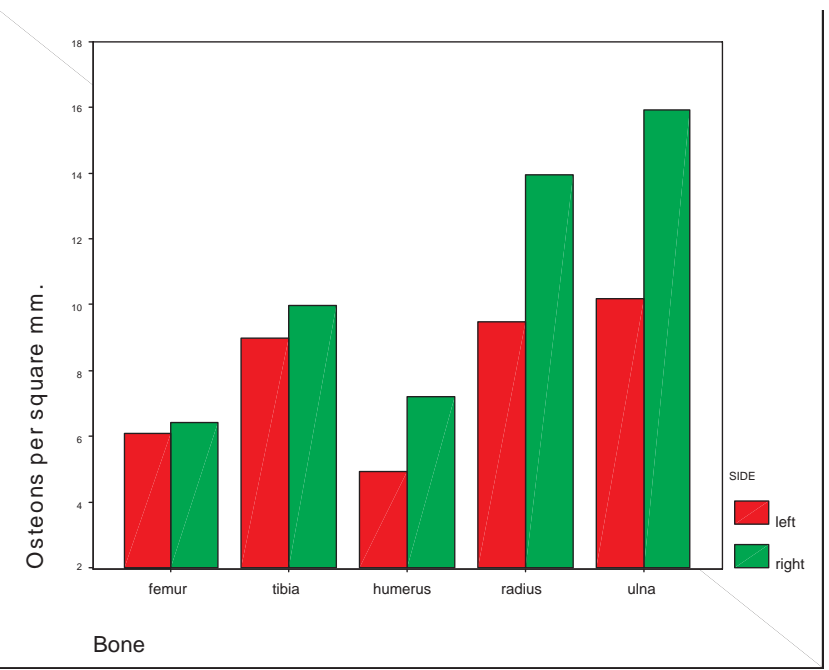

Fig. (1). Bilateral distribution of osteons per sq. mm. in Felis silvestris catus. than in the hindlimb. In both species the radius and ulna exhibit higher densities of secondary osteons and fragments than do other limb bones. The major difference between the two species is that the midshaft humerus is relatively more remodeled in Gallus gallus than in Felis silvestris catus. There is also a proximodistal gradient in densities of haversian structures in Felis silvestris catus, with higher densities in the more proximal sections of the bones, while in Gallus gallus, greatest concentrations are at midshaft with a definite reduction in density toward the proximal and distal extremities (Tables $\mathbf{1}$ and $\mathbf{2}$ ).

\section{Interbone Variation: Bilateral Comparisons}

A complete or partial secondary osteon (haversian system) is an indication of a bone remodeling event. In Felis silvestris catus the right radius and ulna demonstrate the highest remodeling activity based on this observation, particularly at their proximal extremities (Table 1). This implies asymmetric remodeling of the antebrachium in Felis silvestris catus. The humerus, both in terms of overall size and 
remodeling activity, resembles more closely the tibia and femur in contradistinction to the other forelimb bones. Moreover, haversian remodeling in left and right humeri in Felis silvestris catus is symmetrical. Both fore and hindlimb bones in Gallus gallus are also symmetrical in their remodeling (Fig. 2). The asymmetry noted in the Felis silvestris catus forelimb is not present in Gallus gallus; nor is it present in Homo sapiens, as will be discussed below.

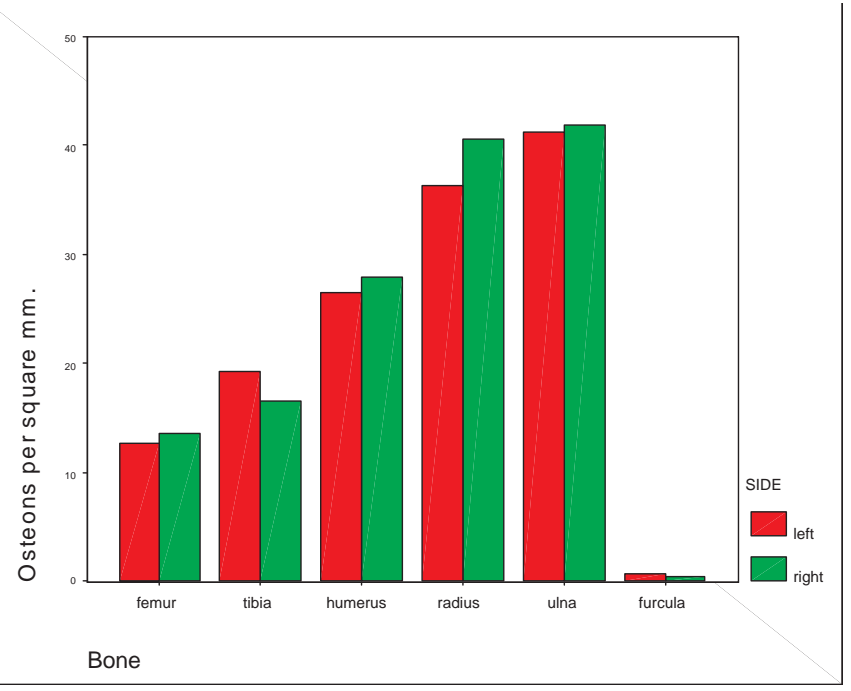

Fig. (2). Bilateral distribution of osteons per sq. mm. in Gallus gallus.

The above results suggest an hypothesis: that forelimb remodeling is asymmetric due to differential limb use from side to side. Some evidence suggests that cats, like many mammals, have a tendency to use one forelimb preferentially in manipulating their environments [31-33]. There is some evidence that forelimb preference has a genetic basis in mammals [34, for example]. This could possibly explain the forelimb asymmetry noted in Felis silvestris catus if haversian remodeling is, in fact, solely a reflection of imposed mechanical loads on bones. If this were indeed the case, then corroborative evidence should be available from the bones of Homo sapiens (It should be noted, however, that the total number of haversian structures is low in all the bones of $\mathrm{Fe}$ lis silvestris catus examined here. The bones are not highly remodeled and the side to side differences between the left and right radii and ulnae may well be due to sampling error.) The bones of Gallus gallus were also examined for evidence of forelimb remodeling asymmetry, as were the forelimbs of Homo sapiens (Fig. 3). It was hypothesized that the chicken would show no asymmetry in its forelimbs, since it was highly unlikely that there could be a preference for greater use of one wing over the other. Humans obviously demonstrate handedness, and in the case of elite athletes such as tennis players, the dominant arm has been demonstrated to show higher bone mineral density and greater bone width than the nondominant arm [35]. (The same group of researchers, however, found no side-to-side differences in upper limb bones following an asymmetric weight training program among non-elite athletes). This suggests, along with evidence from the cat skeleton, that the bones of the human antebrachium should demonstrate asymmetry in remodeling. This would accord with the assumptions of the standard paradigm of skeletal remodeling.

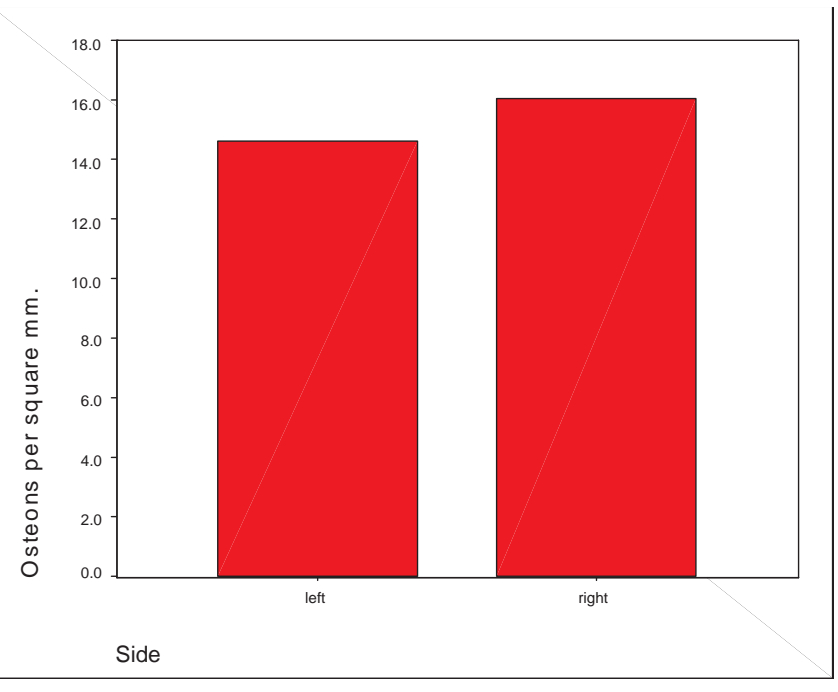

Fig. (3). Bilateral distribution of osteons per sq. mm. in the left and right ulnae of Homo sapiens.

As hypothesized, the chicken skeleton did not show evidence of bilateral asymmetry (Fig. 2). There is no statistically significant difference from side to side. To examine asymmetry in haversian remodeling in humans, undecalcified thin sections were made of the midshafts of 14 pairs of human left and right ulnae. Osteons and fragments per square $\mathrm{mm}$. were examined in four fields located anteriorly, posteriorly, medially and laterally around the perimeter of the midshaft. Cross sectional geometrical properties were also calculated for these midshafts, including cortical area, endosteal area, anteroposterior area moment of inertia, mediolateral area moment of inertia, and polar moment of inertia. Cross sectional geometric properties were size normalized by ulnar length. Wilcoxon signed rank tests demonstrate no significant differences between left and right sides in either haversian structures or cross sectional properties at an experiment wise alpha (Bonferroni corrected) of .05 (Table 3). The standard paradigm would suggest that there should be asymmetry in these properties, given the distinct handedness expressed in human beings. However, no such asymmetry is in evidence. Alternatively, if skeletal anlagen are "translated" from early development to adult structure by conserved response protocols resident in the osteoblast and other connective tissue components, then we would expect there to be no significant difference between sides, and indeed we should see similar responses across vertebrate taxa. Results here collectively support the latter view, and since there was an absence of asymmetry within the human specimens, the most likely explanation of any differences seen in the cat specimen was simply sampling error.

\section{Interbone Variation: Geometric Properties}

Geometric properties of long bone cross sections putatively reflect the results of skeletal growth and remodeling at the macroscopic level, just as histomorphology is believed to reflect these processes at the microscopic level. As with histomorphometric properties, substantial variations in geometric properties were present from one bone to another in our sample (Table 3). Cross sectional geometric properties observed include normalized anteroposterior area moment of 
Table 3. Wilcoxon Signed Rank Tests for Human Ulnae. Expirement Wise Bonferroni Corrected Alpha $=.05$ (.0071 for Individual Comparisons)

\begin{tabular}{|c|c|c|c|c|c|c|c|}
\hline & $\begin{array}{c}\text { Osteon } \\
\text { Fragments }\end{array}$ & $\begin{array}{c}\text { Complete } \\
\text { Osteons }\end{array}$ & $\begin{array}{c}\text { Normalized } \\
\text { Cortical Area }\end{array}$ & $\begin{array}{c}\text { Normalized } \\
\text { Endosteal Area }\end{array}$ & $\begin{array}{c}\text { Normalized A-P } \\
\text { Area Moment } \\
\text { of Inertia }\end{array}$ & $\begin{array}{c}\text { Normalized M-L } \\
\text { Area Moment } \\
\text { of Inertia }\end{array}$ & $\begin{array}{c}\text { Normalized Polar } \\
\text { Area Moment } \\
\text { of Inertia }\end{array}$ \\
\hline \hline $\mathrm{Z}$ & -1.538 & -1.978 & -1.350 & -1.664 & -1.099 & -.157 & -.031 \\
\hline Asymp. Sig. (2-tailed) & .124 & .048 & .177 & .096 & .272 & .875 & .975 \\
\hline
\end{tabular}

inertia $\left(\mathrm{I}_{\mathrm{ap}}\right)$ (Figs. 4-6), normalized mediolateral area moment of inertia $\left(\mathrm{I}_{\mathrm{ml}}\right)$ (Figs. 7-9) and normalized polar moment of inertia (J) (Figs. 10-12). $I_{a p}$ is a measure of the relative resistance to bending along the anteroposterior axis of the bone, $\mathrm{I}_{\mathrm{ml}}$ of the relative resistance to bending along the mediolateral axis, and $\mathbf{J}$ a measure of the relative resistance to torsional deformation [36]. Additionally, cross sectional cortical area (Figs. 13-15) and endosteal area were calculated

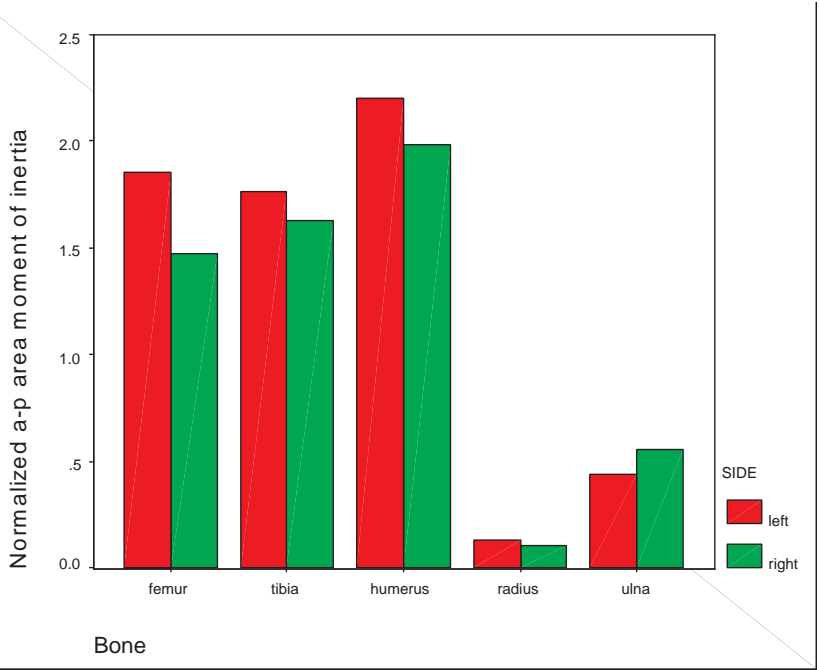

Fig. (4). Normalized anteroposterior area moment of inertia $\left(\mathrm{NI}_{\mathrm{ap}}\right)$ by bone and side in Felis silvestris catus.

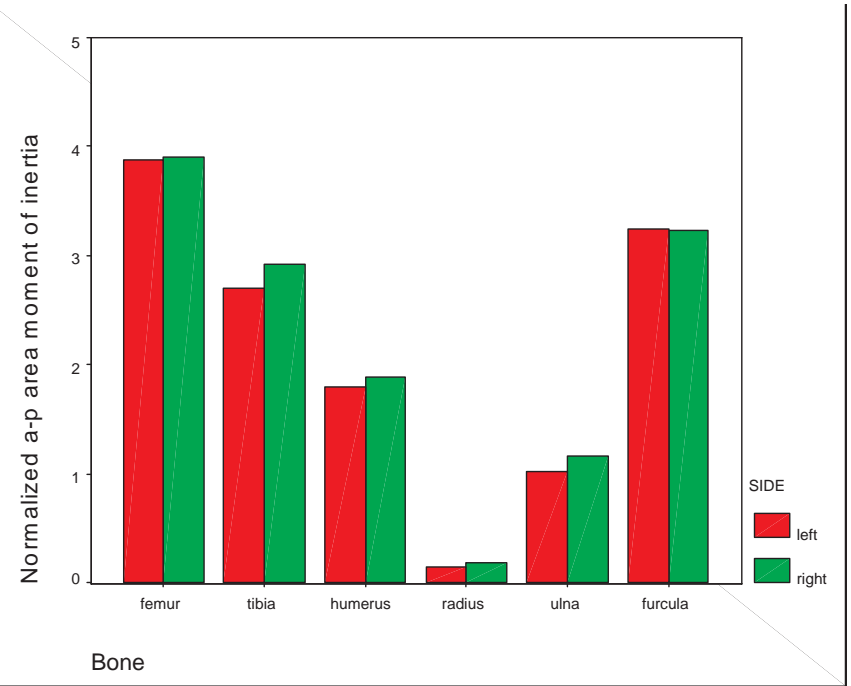

Fig. (5). Normalized anteroposterior area moment of inertia $\left(\mathrm{NI}_{\mathrm{ap}}\right)$ by bone and side in Gallus gallus. for each section. If there are bilateral differences in mechanical loading of bones, and if bone responds primarily to adapt to these differential loadings, we would expect to see asymmetry in these various parameters. However, in general, contralateral members of pairs of bones resemble each other substantially in their cross sectional geometric properties (Figs. 4-15). In Figs. (4-15), the graphs present averages for

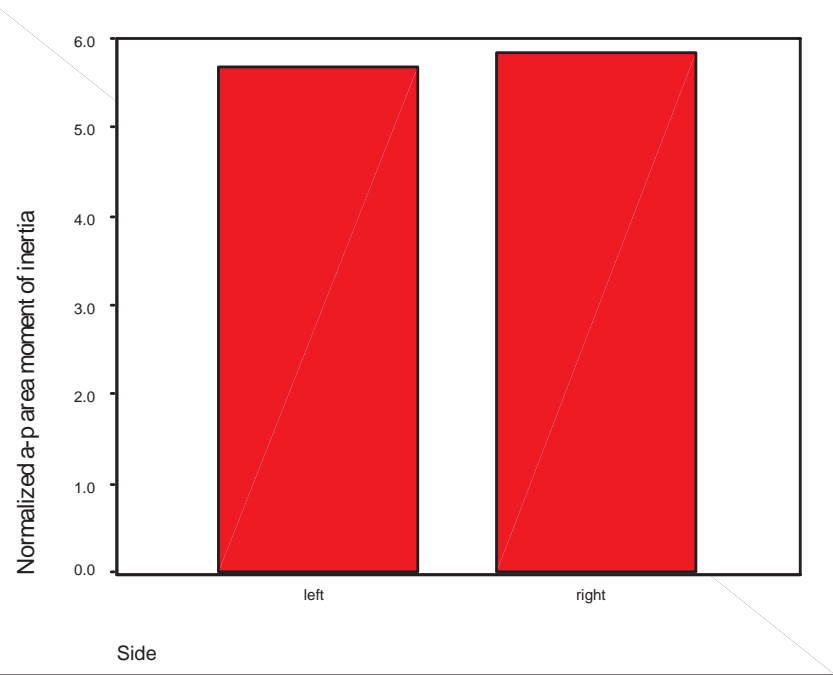

Fig. (6). Normalized anteroposterior area moment of inertia $\left(\mathrm{NI}_{\mathrm{ap}}\right)$ in left and right ulnae of Homo sapiens.

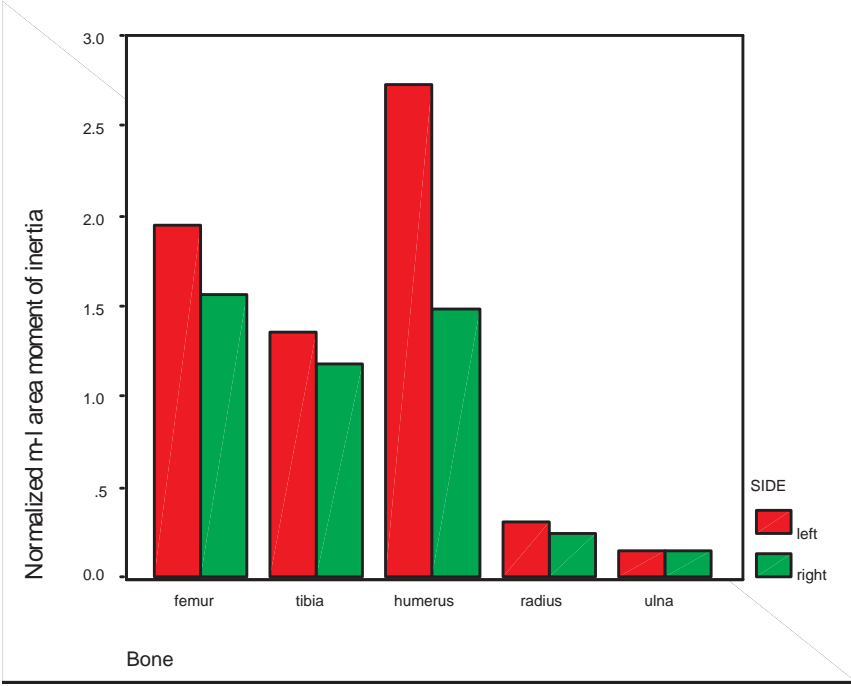

Fig. (7). Normalized mediolateral area moment of inertia $\left(\mathrm{NI}_{\mathrm{ml}}\right)$ by bone and side in Felis silvestris catus. 


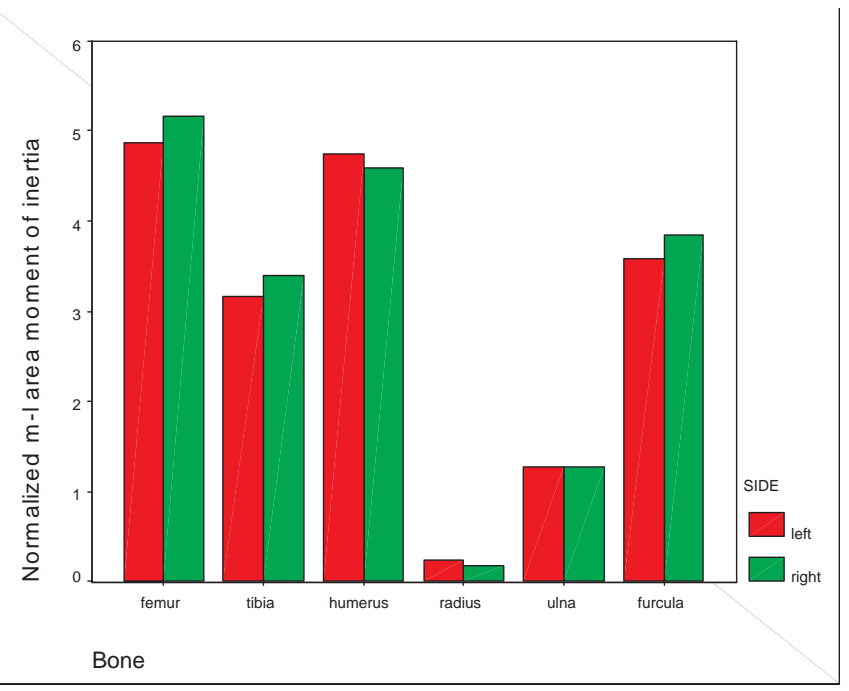

Fig. (8). Normalized mediolateral area moment of inertia $\left(\mathrm{NI}_{\mathrm{ml}}\right)$ by bone and side in Gallus gallus.

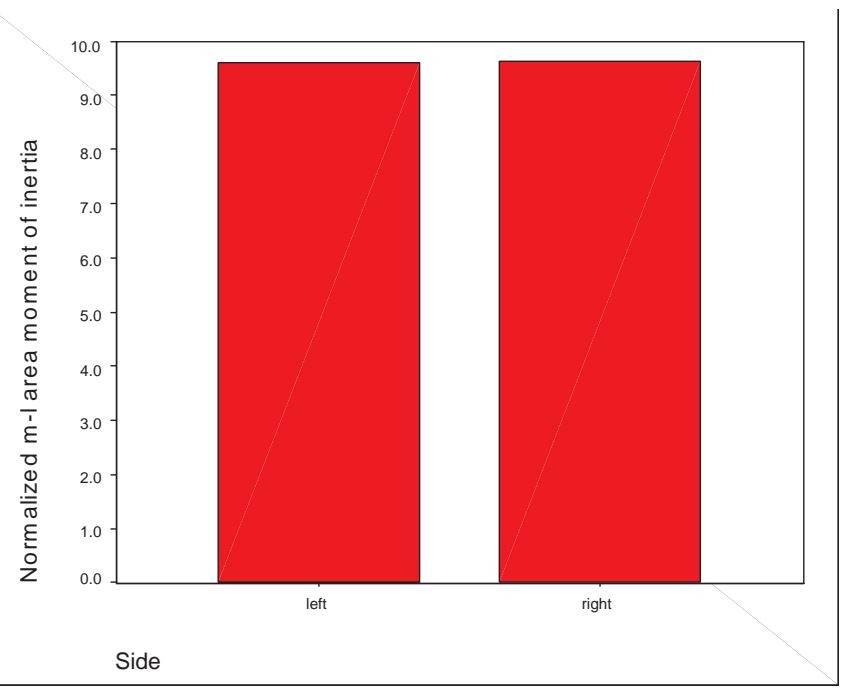

Fig. (9). Normalized mediolateral area moment of inertia $\left(\mathrm{NI}_{\mathrm{ml}}\right)$ in left and right ulnae of Homo sapiens.

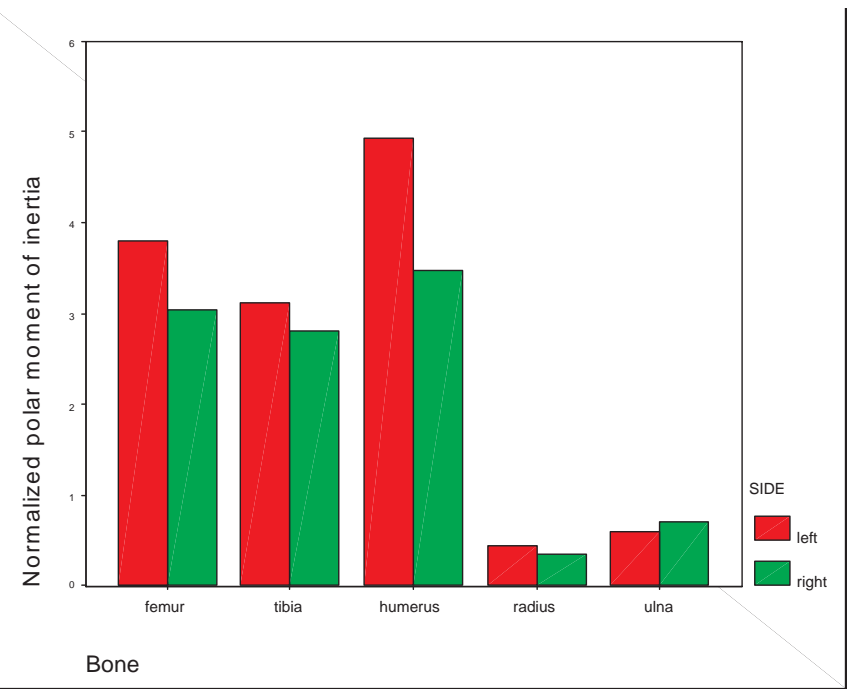

Fig. (10). Normalized polar moment of inertia (NJ) by bone and side in Felis silvestris catus.

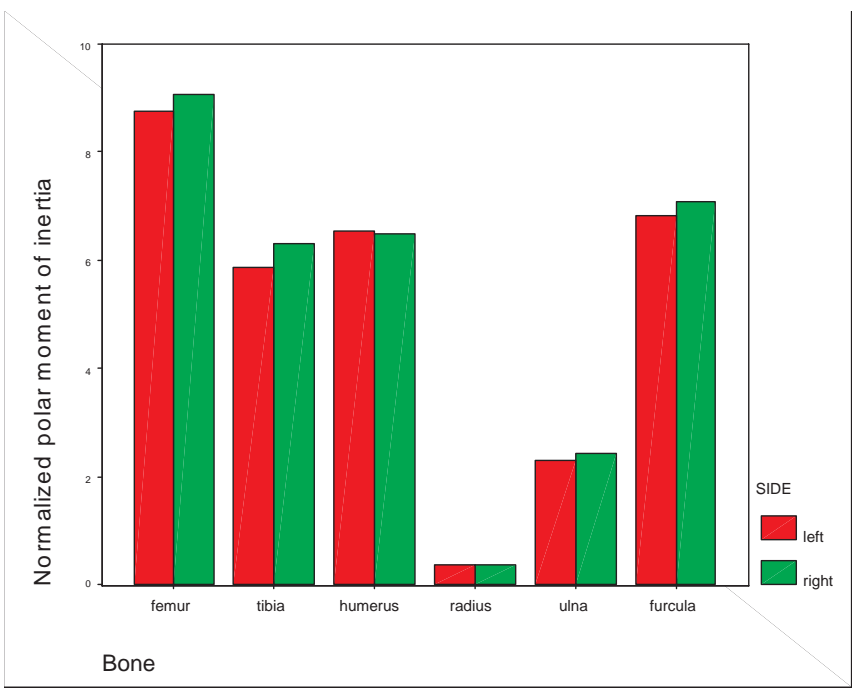

Fig. (11). Normalized polar moment of inertia (NJ) by bone and side in Gallus gallus.

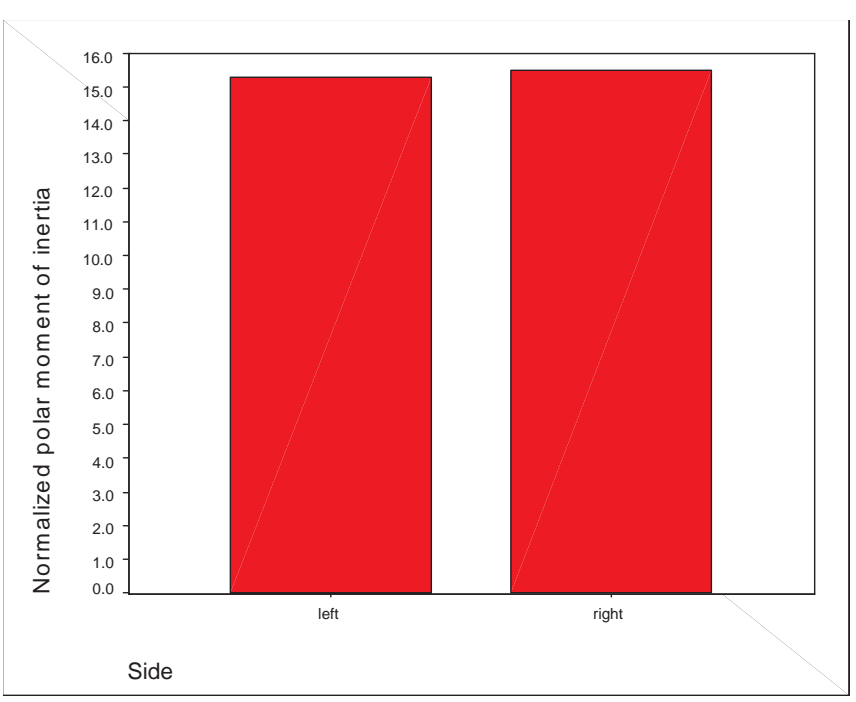

Fig. (12). Normalized polar moment of inertia (NJ) in left and right ulnae of Homo sapiens.

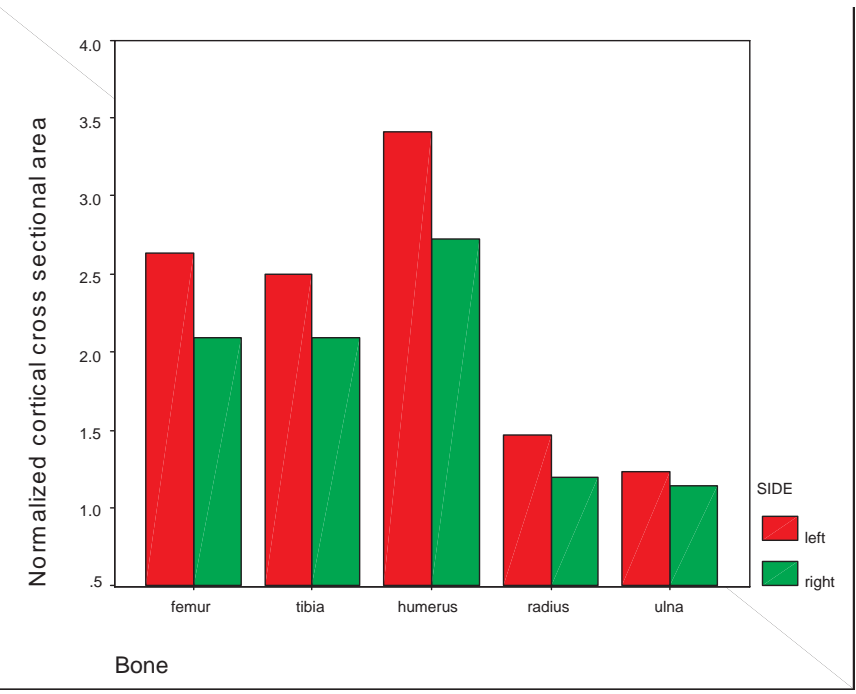

Fig. (13). Normalized cortical area (NCA) by bone and side in Felis silvestris catus. 


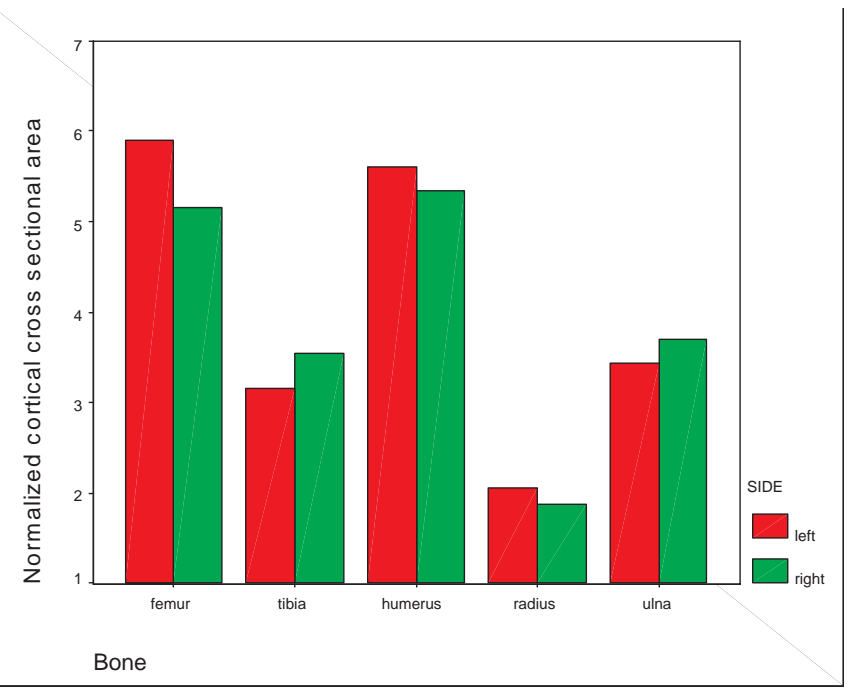

Fig. (14). Normalized cortical area (NCA) by bone and side in Gallus gallus.

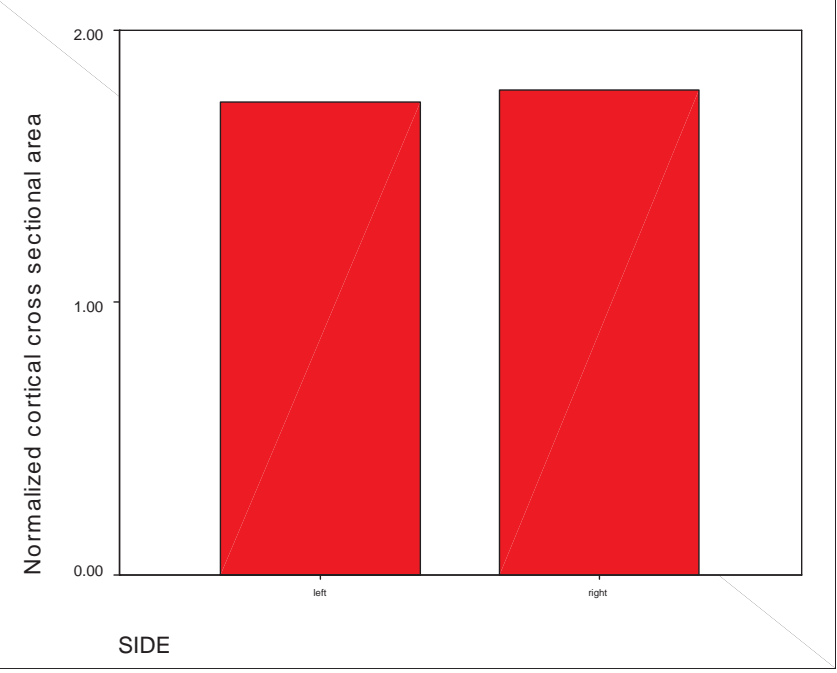

Fig. (15). Normalized cortical area (NCA) in left and right ulnae of Homo sapiens.

all 9 sections in each bone in Felis silvestris catus and Gallus gallus. The data for Homo sapiens represents the midshaft of the bone. Side to side comparisons in Felis silvestris catus and Gallus gallus of normalized cortical area, normalized $\mathrm{I}_{\mathrm{ap}}$, normalized $\mathrm{I}_{\mathrm{ml}}$ and normalized $\mathrm{J}$ demonstrate the general similarity of size and shape for all these geometric properties in both species examined along the length of the bone shaft. Despite apparent differences in microstructure from side to side in the forelimb of the cat, there is no disparity at the macroscopic level. The same appears to be true of humans (Table 2). Differences between left and right midshaft human ulnae are nonsignificant at an experiment-wide alpha level of .05.

\section{Interbone Variation: Homo Sapiens}

Data from Felis silvestris catus and Gallus gallus, and data from the human ulna sample, support the hypothesis that bilateral symmetry in bone macro- and micromorphology is due to underlying genetic and developmental control, and is largely unaffected by differential use from side to side under ordinary circumstances and normal ranges of loading. A further question arises in how histomorphology varies from bone to bone within the skeleton. To explore this question, the midshafts of the right femur, tibia, fibula, humerus, radius, ulna and clavicle were examined in a sample of human skeletons ( $\mathrm{n}=39 ; 23$ female, 16 male). The ulnae in this sample include the right side members of the 14 pairs of ulnae observed for side to side differences. Histomorphometric data were normalized to account for bone resorption by recomputing osteon and fragment densities per sq. mm. on only that percent of the field of view which has not been resorbed. The resulting normalized densities of osteons and fragments per square millimeter are therefore densities of just the unresorbed bone that remains in the section. Therefore, these can be directly compared to data from midshaft sections of the same bones in Felis silvestris catus and Gallus gallus.

The most prominent difference in the human sample occurs between the sexes. Females show considerably greater numbers of fragments per sq. mm. than do males. Osteons and osteon fragments are relics of the remodeling process and serve as proxies for remodeling events. It is well established that human females, particularly following menopause, demonstrate greater rates of bone resorption and remodeling of remaining bone $[17,37]$. In this sample, females show greater numbers of osteon fragments for all bones examined (Table 4). Females also show greater amounts of resorption in all bones, except the clavicle and fibula (Fig. 16).

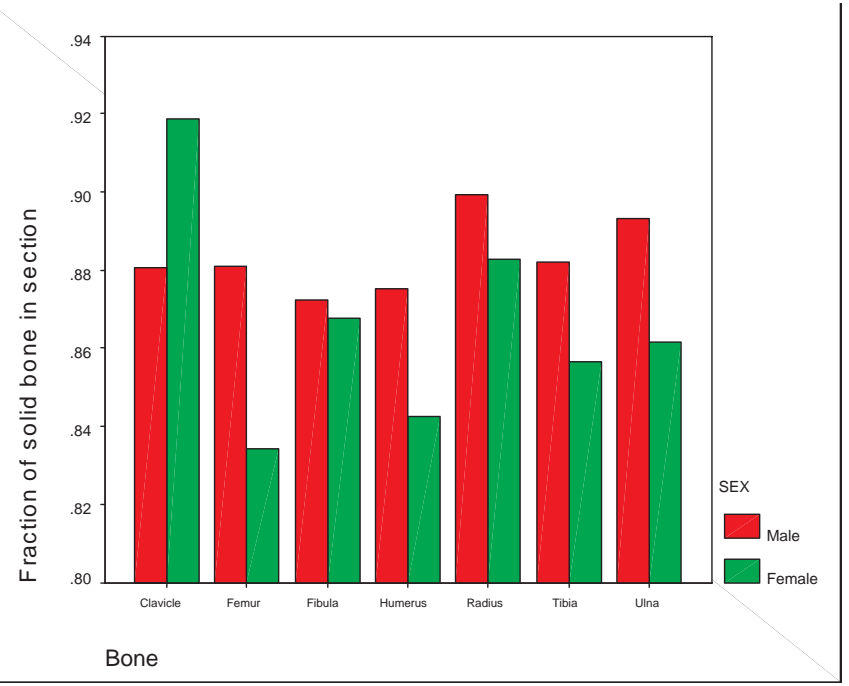

Fig. (16). Percent of field composed of solid bone in males and females, Homo sapiens only.

There are significant differences in mean complete and fragmentary osteon densities among bones (Table 4). The proximal bones of both upper and lower limb show lower osteon and fragment densities than do the more distal elements. This echoes our findings for Gallus gallus and Felis silvestris catus as noted earlier. In Homo sapiens, a two way ANOVA with sex and bone types as main effects demonstrates that sex is not a significant factor affecting osteon density, whereas osteon densities are significantly different among bones (Table 5). By contrast, a similar analysis 
Table 4. Complete Osteons and Osteon Fragments Per Square mm. by Bone in Homo sapiens. (a) Osteons per sq. mm. (b) Osteon Fragments per sq. mm.

(a) Osteons per sq. mm.

\begin{tabular}{|c|c|c|c|c|c|c|c|}
\hline & & \multicolumn{3}{|c|}{ Male } & \multicolumn{3}{|c|}{ Female } \\
\hline & & Mean & Std Deviation & Valid N & Mean & Std Deviation & Valid N \\
\hline \multirow{5}{*}{ Bone } & Femur & 58.14 & 11.61 & $\mathrm{~N}=29$ & 57.42 & 14.40 & $\mathrm{~N}=38$ \\
\hline & Fibula & 53.06 & 7.57 & $\mathrm{~N}=17$ & 53.29 & 13.71 & $\mathrm{~N}=17$ \\
\hline & Humerus & 62.26 & 13.88 & $\mathrm{~N}=19$ & 59.95 & 11.32 & $\mathrm{~N}=19$ \\
\hline & Radius & 50.38 & 8.30 & $\mathrm{~N}=13$ & 57.15 & 14.43 & $\mathrm{~N}=20$ \\
\hline & Ulna & 52.58 & 10.88 & $\mathrm{~N}=12$ & 52.95 & 14.13 & $\mathrm{~N}=20$ \\
\hline
\end{tabular}

(b) Osteon Fragments per sq. mm.

\begin{tabular}{|c|c|c|c|c|c|c|c|}
\hline & & \multicolumn{3}{|c|}{ Male } & \multicolumn{3}{|c|}{ Female } \\
\hline & & Mean & Std Deviation & Valid $N$ & Mean & Std Deviation & Valid N \\
\hline \multirow[t]{5}{*}{ Bone } & Femur & 19.28 & 7.40 & $\mathrm{~N}=29$ & 23.42 & 8.52 & $\mathrm{~N}=38$ \\
\hline & Fibula & 23.41 & 9.32 & $\mathrm{~N}=17$ & 27.76 & 15.49 & $\mathrm{~N}=17$ \\
\hline & Humerus & 20.37 & 7.48 & $\mathrm{~N}=19$ & 21.68 & 10.54 & $\mathrm{~N}=19$ \\
\hline & Radius & 24.00 & 7.16 & $\mathrm{~N}=13$ & 24.90 & 10.41 & $\mathrm{~N}=20$ \\
\hline & Ulna & 20.92 & 10.72 & $\mathrm{~N}=12$ & 27.85 & 11.80 & $\mathrm{~N}=20$ \\
\hline
\end{tabular}

Table 5. ANOVA: Osteons per sq. mm. by Sex and Bone in Homo sapiens

\begin{tabular}{|c|c|c|c|c|c|c|c|}
\hline \multirow{5}{*}{ Osteons per sq. mm. } & Main Effects & (Combined) & 2758.579 & 7 & 394.083 & 2.393 & .022 \\
\hline & & Bone & 2744.371 & 6 & 457.395 & 2.777 & .012 \\
\hline & 2-Way Interactions & Sex * Bone & 443.530 & 6 & 73.922 & .449 & .846 \\
\hline & \multicolumn{2}{|c|}{ Residual } & 44964.592 & 273 & 164.705 & & \\
\hline & \multicolumn{2}{|c|}{ Total } & 48052.997 & 286 & 168.017 & & \\
\hline
\end{tabular}


demonstrates that element type within the skeleton is not a significant factor affecting the density of osteon fragments. However, there is a significant difference in mean osteon fragment density between males and females (Table 6 ).

\section{Fore Limb - Hind Limb Comparisons in Homo sapiens}

The forelimb and the hindlimb are loaded in different manners during locomotion. This is obviously true in Homo sapiens. Under the standard paradigm of bone remodeling, it would be expected that the human lower limb should show much greater levels of haversian remodeling than would the upper limb. However, results of analysis of variance show that the differences in osteon and fragment densities are nonsignficant between upper and lower limbs in Homo sapiens. When upper limb is compared to lower limb, only the percentage of section composed of solid bone approaches significance between limbs (Table 7). This parameter is a measure of the amount of resorption of bone, and likely reflects the differential effect of osteoporosis on the upper and lower limb. Interestingly, in Felis silvestris catus, the forelimb has significantly higher osteon and fragment densities than does the hindlimb.

\section{Principal Components Analyses}

Principal components analysis (PCA) provides a means with which to examine variation within a data set by summarizing them as a series of orthogonal axes. These axes, or principal components, are so arranged that variance away from each axis is minimized. Each component thus accounts for a percentage of the variance in the sample. The first component explains the largest percentage of variance, the second the second highest percentage of variance and so forth [38]. The principal components derived are not correlated with one another, but the variables which describe the sample can be correlated with them to one degree or another. By this means, the variance in a sample defined by a number of variables can be reduced to a number of principal components. The correlation of variables with these components can then be used to describe how well the components explain variance within the sample.

For the human data, PCA was performed using fraction of the field of view composed of solid bone, normalized osteons per sq. mm. and normalized osteon fragments per sq. $\mathrm{mm}$. as the variables in the analysis (Table 8). The first two principal components extracted account for over $74 \%$ of the variance in the sample. For the first principal component, normalized osteon density loads highly positively, while fraction of solid bone in the section loads highly negatively. Thus, it appears that this component represents variation in haversian remodeling from bone to bone as measured by osteon density, and accounts for about $40 \%$ of the variation in the sample. For the second principal component, the fraction of the field composed of solid bone and the normalized density of osteons per square millimeter load negatively, while normalized osteon fragments load highly positively. This factor appears to represent the secondary remodeling of already existing haversian bone, and accounts for an almost equal portion of the variation in the sample (about 35\%). For the third principal component, all three variables load positively, osteon density and fraction of solid bone in the section especially so. This factor accounts for $25.6 \%$ of the variation in the sample. Both osteon density and fragment density load positively on the first principal component, though osteon density loads higher than fragment density. Fragment density, however, loads extremely positively on the second component while both osteon density and percent of field composed of solid bone load negatively. Osteon fragment density stands out distinctly on the second principal component.

A second PCA was conducted on data available for Homo sapiens, Felis silvestris catus and Gallus gallus. Variables included in the analysis included three histological variables: osteons per square mm., osteon fragments per square mm., and percent of the field composed of haversian bone. They also include two measures of bone mass or robusticity: normalized cortical area and normalized endosteal area; and three measures of bone cross sectional geometry: normalized $\mathrm{I}_{\mathrm{ap}}$, normalized $\mathrm{I}_{\mathrm{ml}}$, and normalized J. While principal components analysis extracted 7 principal components, the first four of these account for over $90 \%$ of the variance in the sample (Table 9). The first principal component accounts for $45.5 \%$ of the variance in the sample. The three measures of bone geometry load very highly positively on this component, and the two measures of bone mass load moderately high on this component. Two of the three histomorphological variables load negatively on this component. While all the measures of bone strength and mass have been

Table 6. ANOVA: Osteon Fragments per sq. mm. by Sex and Bone in Homo sapiens

\begin{tabular}{|c|c|c|c|c|c|c|c|}
\hline \multirow{5}{*}{$\begin{array}{l}\text { Osteon fragments per sq. } \\
\qquad \mathrm{mm} .\end{array}$} & Main Effects & (Combined) & 1948.143 & 7 & 278.306 & 2.785 & .008 \\
\hline & & Bone & 750.689 & 6 & 125.115 & 1.252 & .280 \\
\hline & 2-Way Interactions & Sex $*$ Bone & 381.180 & 6 & 63.530 & .636 & .702 \\
\hline & \multicolumn{2}{|c|}{ Residual } & 27281.230 & 273 & 99.931 & & \\
\hline & \multicolumn{2}{|c|}{ Total } & 29492.627 & 286 & 103.121 & & \\
\hline
\end{tabular}


Table 7. ANOVA: Osteons, Fragments, Solid Bone in Section by Limb and Bone in Homo sapiens. (a) Osteons per sq. mm. by Limb and Sex. (b) Osteon Fragments per sq. mm. by Limb and Sex. (c) Fraction of Section Composed of Solid Bone by Limb and Sex

(a) Osteons per sq. mm. by Limb and Sex in Homo sapiens

\begin{tabular}{|c|c|c|c|c|c|c|c|}
\hline & & & \multicolumn{5}{|c|}{ Unique Method } \\
\hline & & & Sum of Squares & df & Mean Square & $\mathbf{F}$ & Sig. \\
\hline \multirow{7}{*}{ Osteons per sq. mm. } & Main Effects & (Combined) & 188.411 & 2 & 94.205 & .557 & .574 \\
\hline & & Limb & 184.124 & 1 & 184.124 & 1.089 & .298 \\
\hline & & Sex & 6.627 & 1 & 6.627 & .039 & .843 \\
\hline & 2-Way Interactions & Limb*Sex & 22.091 & 1 & 22.091 & .131 & .718 \\
\hline & \multicolumn{2}{|c|}{ Model } & 196.778 & 3 & 65.593 & .388 & .762 \\
\hline & \multicolumn{2}{|c|}{ Residual } & 47856.219 & 283 & 169.103 & & \\
\hline & \multicolumn{2}{|c|}{ Total } & 48052.997 & 286 & 168.017 & & \\
\hline
\end{tabular}

(b) Osteon Fragments per sq. mm. by Limb and Sex in Homo sapiens

\begin{tabular}{|c|c|c|c|c|c|c|c|}
\hline & & & \multicolumn{5}{|c|}{ Unique Method } \\
\hline & & & Sum of Squares & df & Mean Square & $\mathbf{F}$ & Sig. \\
\hline \multirow{7}{*}{$\begin{array}{l}\text { Osteon fragments } \\
\text { per sq. mm. }\end{array}$} & Main Effects & (Combined) & 1088.461 & 2 & 544.231 & 5.423 & .005 \\
\hline & & Limb & 28.216 & 1 & 28.216 & .281 & .596 \\
\hline & & Sex & 1045.939 & 1 & 1045.939 & 10.422 & .001 \\
\hline & 2-Way Interactions & $\operatorname{Limb}^{*} \operatorname{Sex}$ & 8.587 & 1 & 8.587 & .086 & .770 \\
\hline & \multicolumn{2}{|c|}{ Model } & 1090.353 & 3 & 363.451 & 3.621 & .014 \\
\hline & \multicolumn{2}{|c|}{ Residual } & 28402.274 & 283 & 100.361 & & \\
\hline & \multicolumn{2}{|c|}{ Total } & 29492.627 & 286 & 103.121 & & \\
\hline
\end{tabular}

(c) Fraction of Section Composed of Solid Bone by Limb and Sex in Homo sapiens

\begin{tabular}{|c|c|c|c|c|c|c|c|}
\hline & & & \multicolumn{5}{|c|}{ Unique Method } \\
\hline & & & Sum of Squares & df & Mean Square & $\mathbf{F}$ & Sig. \\
\hline \multirow{7}{*}{$\begin{array}{l}\text { Fraction of solid } \\
\text { bone in section }\end{array}$} & Main Effects & (Combined) & $5.163 \mathrm{E}-02$ & 2 & $2.582 \mathrm{E}-02$ & 5.566 & .004 \\
\hline & & Limb & $1.762 \mathrm{E}-02$ & 1 & $1.762 \mathrm{E}-02$ & 3.798 & .052 \\
\hline & & Sex & $3.582 \mathrm{E}-02$ & 1 & $3.582 \mathrm{E}-02$ & 7.722 & .006 \\
\hline & 2-Way Interactions & $\operatorname{Limb}^{*}$ Sex & $5.141 \mathrm{E}-03$ & 1 & $5.141 \mathrm{E}-03$ & 1.108 & .293 \\
\hline & \multicolumn{2}{|c|}{ Model } & $6.523 \mathrm{E}-02$ & 3 & $2.174 \mathrm{E}-02$ & 4.688 & .003 \\
\hline & \multicolumn{2}{|c|}{ Residual } & 1.313 & 283 & $4.638 \mathrm{E}-03$ & & \\
\hline & \multicolumn{2}{|c|}{ Total } & 1.378 & 286 & $4.817 \mathrm{E}-03$ & & \\
\hline
\end{tabular}


Table 8. Principal Components Analysis, Homo sapiens Only: Eigenvalues and Factor Score Coefficient Matrix. (Factor Scores for Individual Specimens are Presented in Appendix A2)

\section{Eigenvalues}

\begin{tabular}{|c|c|c|c|}
\hline Component & & $\begin{array}{c}\text { Variance } \\
\text { Explained }\end{array}$ & $\begin{array}{c}\text { Cumulative Variance } \\
\text { Explained }\end{array}$ \\
\hline \hline 1 & 1.193 & 39.758 & 39.758 \\
\hline 2 & 1.038 & 34.594 & 74.352 \\
\hline 3 & .769 & 25.648 & 100.000 \\
\hline
\end{tabular}

Factor Score Coefficient Matrix

\begin{tabular}{|c|c|c|c|}
\hline & \multicolumn{3}{|c|}{ Component } \\
\cline { 2 - 4 } & $\mathbf{1}$ & $\mathbf{2}$ & $\mathbf{3}$ \\
\hline \hline Normalized osteons per sq. mm. & .699 & -.470 & .539 \\
\hline Normalized fragments per sq. mm. & .256 & .895 & .364 \\
\hline Fraction of solid bone in section & -.799 & -.124 & .588 \\
\hline
\end{tabular}

Extraction Method: Principal Component Analysis.

Table 9. Principal Components Analysis, Felis silvestris catus, Gallus gallus and Homo sapiens: Eigenvalues and Factor Score Coefficient Matrix. (Factor Scores for Individual Specimens are Presented in Appendix A3)

Eigenvalues

\begin{tabular}{|c|c|c|c|}
\hline Component & & Variance Explained & Cumulative Variance Explained \\
\hline \hline 1 & 3.632 & 45.405 & 45.405 \\
\hline 2 & 1.917 & 23.960 & 69.365 \\
\hline 3 & 1.101 & 13.768 & 90.395 \\
\hline 4 & .581 & 7.262 & 96.458 \\
\hline 5 & .485 & 6.064 & 98.734 \\
\hline 6 & .182 & 2.276 & 100.000 \\
\hline
\end{tabular}

\section{Factor Score Coefficient Matrix}

\begin{tabular}{|c|c|c|c|c|c|c|c|}
\hline & \multicolumn{7}{|c|}{ Component } \\
\hline & 1 & 2 & 3 & 4 & 5 & 6 & 7 \\
\hline osteons per square mm. & -.316 & .350 & .757 & -.318 & .322 & .001 & -.011 \\
\hline osteon fragments per square $\mathrm{mm}$. & .412 & .653 & -.204 & .420 & .429 & .026 & -.023 \\
\hline percent haversian bone: mean of four fields & -.327 & .598 & .485 & .380 & -.395 & -.002 & .009 \\
\hline normalized endosteal cross sectional area & .567 & -.632 & .353 & .249 & .092 & -.290 & .020 \\
\hline normalized cortical cross sectional area & .615 & -.606 & .351 & .182 & .033 & .311 & .013 \\
\hline normalized anteroposterior area moment of inertia & .931 & .194 & .054 & -.132 & -.133 & -.019 & -.240 \\
\hline normalized mediolateral area moment of inertia & .900 & .346 & -.003 & -.154 & -.070 & -.009 & .204 \\
\hline normalized polar moment of inertia & .938 & .295 & .020 & -.150 & -.097 & -.013 & .032 \\
\hline
\end{tabular}

normalized by bone length, this component is still clearly a "size" component, reflecting relative robusticity. It is not surprising that measures of size and robusticity should account for almost half the variance in a sample made up of three taxa as diverse as the three analyzed here. The second principal component explains $24 \%$ of the variance in the sample. This component appears to represent variation in haversian remodeling. Osteon fragments per square millimeter and percent of field composed of haversian bone load strongly positively on this component, while cortical and endosteal area load strongly negatively. The third principal component explains $13.8 \%$ of the variance in the sample. Number of osteons per square millimeter loads highly positively on this component, and so this component likely rep- 
resents variation in numbers of secondary osteons. The first three principal components together explain over $83 \%$ of the variance in the sample.

\section{DISCUSSION}

Given the diversity of locomotor patterns of the three species examined here, and the resulting environmental differences in the loading of their appendicular skeletons, the histomorphological patterns observed suggest that remodeling is subject to modulation by intrinsic developmental factors, in addition to any effects of mechanical loading [41]. The cohesion within the patterns of remodeling in the three species examined suggests an underlying genetic basis to their similarity. Numerous workers, notably initiated by Bertram and Swartz [13], have questioned the real explanatory power of the so called "Wolff's law" in the remodeling of bone. Results of this study accord with the notion that factors other than simple mechanical loading may be the primary determinants of skeletal remodeling. Additional vertebrate taxa need to be examined in order to resolve this issue more fully. Neither histomorphology nor cross sectional properties differ by side in our sample of human ulnas. The lack of such asymmetry in haversian structures suggests that habitual asymmetric loading under normal circumstances is too subtle to permit detection. This conclusion is opposite that of the traditional anthropological model of cortical bone haversian remodeling.

This work is a pilot study. In the future we hope to accumulate further data on the taxa already examined here, as well as to expand the sample and include wild specimens. Such work is already ongoing in our laboratory. One of the purposes of the principal components analyses presented here are to assess variation in cortical bone properties across species. As noted above, principal components derived are not correlated with one another, but the variables which describe the sample can be correlated with them to one degree or another. The correlation of variables with these components can then be used to describe how the components explain variance within the sample. When data from all three species are included in a principal components analysis, the first component, responsible for almost half the variance in the sample, is, not surprisingly, a size component. The measures of the geometric properties of the sections, which serve as proxies for size, correlate highly on that component. Osteon fragment density has a very high positive correlation with the second component while both osteon density and percent of field composed of solid bone correlate negatively. Osteon fragment density stands with a distinctively high correlation with the second principal component. Percent of the field composed of haversian bone correlates only slightly less highly. This component explains a quarter of the variance in the sample, and suggests that modeling and remodeling of haversian bone is a greater source of variation than the density of complete osteons in cross-species comparisons. This may be related to the wide size range of the species examined, or to differences in developmental ages of the specimens. In future research we plan to examine additional taxa of a greater size range and at additional developmental stages. In the other principal components analysis presented, only human specimens were included. In this analysis we examined variation within a single species (Homo sapiens) among three histomorphological variables: density of com- plete osteons, density of fragmentary osteons, and percentage of field composed of haversian bone. We found that osteon density is highly correlated with the first principal component, while fragment density is only poorly correlated with this component. Percent of field composed of haversian bone is highly negatively correlated with the first component. Osteon fragment density is highly positively correlated with the second component. These results suggest that within species, certainly among Homo sapiens, densities of complete osteons are independent of densities of fragmentary osteons. Future research will include examination of the effects of body size, developmental phase and rates of development on histomorphometric and geometric properties of cortical bone.

If, indeed, variation in histomorphological and cross sectional properties of cortical bone, particularly human cortical bone, owe more to underlying genetic regulatory mechanisms and less to environmental factors, then this throws into question assumptions made about activity levels or activity patterns deduced from cross sectional geometry and histomorphology of human cortical bone. Major studies which have shown bone hypertrophy in response to noninvasive loading [39, 40, 42] have been carried out on subadults. Similar effects on human adults have not been demonstrated. As has been shown here, there appears to be no significant effect in adults of asymmetric loading of the forelimb. Persistent scars of union of fractured bones in human adults are a further indication of the lack of response of bone tissue to mechanical loading in adults [5]. Further, it has been shown that when long bone length, age and sex are fully considered, perceived populational differences in femoral cortical thickness are nonsignificant [43]. All of these factors throw into question how much conjecture is permissible about human activities solely from evidence of skeletal remodeling. Indeed, in this study the most important determinant of variation in histomorphometry is that due to sex, which is clearly caused by differences in genetics and endocrine environments in males and females.

Within the diaphysis of a long bone, the primary site of ossification is approximately at midshaft (or more accurately located by the site at which the nutrient artery first penetrates the endosteum) and the diaphysis subsequently ossifies towards the two ends of the bone. Therefore, the midshaft has the oldest "ossification-age," with proximal and distal ends of the diaphysis having a younger "ossification-age." Since remodeling should in part reflect age, the evidence presented for a greater amount of remodeling at midshaft may at least partly be explained by the greater 'ossification-age' of the midshaft. Indeed, this supports the case for genetically controlled processes rather than Wolffian ones. Additionally, as has long been known, among mammals one end of a particular bone may grow much faster than the other. Humans demonstrate the typical mammalian pattern. In Homo sapiens, the more rapidly growing end (which is also that at which epiphyseal union is most delayed) in each of the major long bones is as follows: femur - distal; tibia - proximal; humerus - proximal; radius - distal; ulna - distal [44]. The bone in the "growing end" of the bone is therefore developmentally younger than the bone at the midshaft. The similar growth behavior of the knee epiphyses is largely a consequence of their origin within the same HOX territory and accounts for the marked stability of the crural index (femur/tibia) in the 
hindlimb but a much more varied brachial index in the forelimb, where the primary growth plates do not share a territory [45]. In our study this same pattern is revealed by the higher densities of haversian structures at midshaft. Additionally, the distal ends of the bones, which are developmentally younger than the midshaft and proximal ends, show gradually lower osteon densities from the midshaft to the distal end. This is especially apparent in the radius and ulna of Felis silvestris catus, and is clearly the result of genetically programmed growth, rather than as a result of mechanical loading.

\section{CONCLUSIONS}

Obviously the locomotor anatomy of Felis silvestris catus and Gallus gallus vary significantly from each other and from that of Homo sapiens, and loading environments for the human fore and hindlimb are substantially different from that of a cursorial quadruped or bird. However, it can be expected that the types of variation present in the appendicular skeletons of Felis silvestris catus and Gallus gallus will also evince themselves in other vertebrate species, including humans. There are many claims about the sensitivity of bone as a "dynamic tissue" with intricate responses to loading, yet the external morphology of left and right bones from an individual can match nearly perfectly and yet have nonidenti- cal loading histories (forelimbs in humans for example). Data thus far collected suggest that this differential loading may be relatively unimportant as an influence on rates and patterns of skeletal remodeling in adult humans. We suggest that the underlying conservatism of regulatory genes affecting the skeletal system among vertebrates may be a much greater influence on skeletal morphology, both at the macroscopic and microscopic levels.

In summary, bone remodeling is not uniform throughout the skeleton. There is no universal, tissue-wide response of bone to age. Independent bones behave as independent organs, demonstrating substantial variation in remodeling, both among different skeletal elements, and within different regions of a single bone. Evidence presented here suggests that bone morphology, at both the microscopic and macroscopic level, is largely the result of genetically controlled processes.

\section{ACKNOWLEDGMENTS}

This research is supported in part by the New York Chiropractic College Department of Clinical Anatomy, Department of Research, and Division of Academic Affairs. We wish to thank the reviewers for their comments, which have been of immense value. We would like to thank one particular reviewer for insights regarding the growth processes of bone.

Appendix A1. Raw data for the human ulna cross section specimens. AGE $=$ chronological age in years. SEX: $1=$ male, $2=$ female. Osteons $=$ complete osteons per square millimeter. Fragments $=$ fragmentary osteons per square millimeter. NIap $=$ normalized area moment of inertia along the anteroposterior axis. NIml = normalized area moment of inertia along the mediolateral axis. $\mathrm{NJ}=$ polar moment of inertia.

\begin{tabular}{|c|c|c|c|}
\hline \multicolumn{2}{|c|}{ SPECIMEN } & \multicolumn{2}{|c|}{ SIDE } \\
\hline \multirow{5}{*}{9711} & SEX & 1 & 1 \\
\hline & osteons & 13.1 & 13.4 \\
\hline & NIap & 6.4 & 4.99 \\
\hline & NIml & 9.41 & 7.15 \\
\hline & NJ & 15.81 & 12.14 \\
\hline \multirow{4}{*}{9712} & AGE & 84 & 84 \\
\hline & SEX & 2 & 2 \\
\hline & NIml & 3.95 & 3.67 \\
\hline & $\mathrm{NJ}$ & 6.69 & 5.93 \\
\hline \multirow{6}{*}{9713} & AGE & 76 & 76 \\
\hline & SEX & 2 & 2 \\
\hline & osteons & 15.9 & 17.2 \\
\hline & fragments & 12.7 & 15.6 \\
\hline & NIap & 4.69 & 5.62 \\
\hline & NIml & 7.63 & 12.75 \\
\hline
\end{tabular}


(Appendix A1) contd...

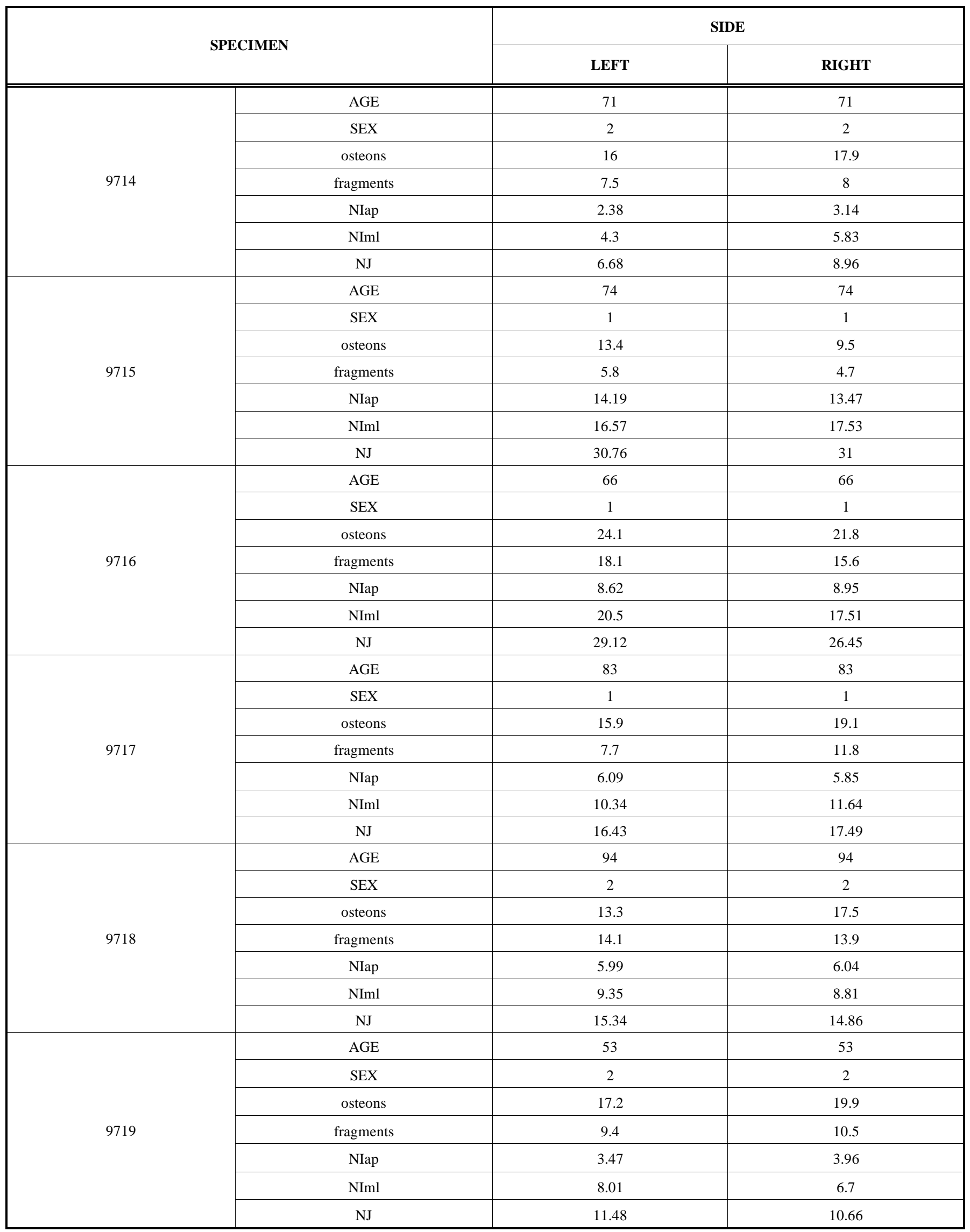


(Appendix A1) contd....

\begin{tabular}{|c|c|c|c|}
\hline \multirow{2}{*}{\multicolumn{2}{|c|}{ SPECIMEN }} & \multicolumn{2}{|c|}{ SIDE } \\
\hline & & LEFT & RIGHT \\
\hline \multirow{7}{*}{9720} & AGE & 87 & 87 \\
\hline & SEX & 2 & 2 \\
\hline & osteons & 15.8 & 17.5 \\
\hline & fragments & 9.2 & 15.2 \\
\hline & NIap & 3.52 & 4.53 \\
\hline & NIml & 4.35 & 4.66 \\
\hline & NJ & 7.87 & 9.19 \\
\hline \multirow{7}{*}{9721} & $\mathrm{AGE}$ & 72 & 72 \\
\hline & SEX & 1 & 1 \\
\hline & osteons & 13.7 & 15.8 \\
\hline & fragments & 8 & 6.5 \\
\hline & NIap & 5.2 & 6.09 \\
\hline & NIml & 8.89 & 10.49 \\
\hline & NJ & 14.09 & 16.58 \\
\hline \multirow{7}{*}{9722} & AGE & 100 & 100 \\
\hline & SEX & 2 & 2 \\
\hline & osteons & 12.1 & 14.1 \\
\hline & fragments & 14.2 & 21.2 \\
\hline & NIap & 3.86 & 3.28 \\
\hline & NIml & 6.84 & 6.1 \\
\hline & $\mathrm{NJ}$ & 10.7 & 9.38 \\
\hline \multirow{7}{*}{9723} & AGE & 77 & 77 \\
\hline & SEX & 1 & 1 \\
\hline & osteons & 13.7 & 18 \\
\hline & fragments & 10.7 & 9 \\
\hline & NIap & 5.75 & 6.77 \\
\hline & NIml & 13.2 & 11.99 \\
\hline & NJ & 18.94 & 18.76 \\
\hline \multirow{7}{*}{9801} & AGE & 65 & 65 \\
\hline & SEX & 1 & 1 \\
\hline & osteons & 14.8 & 16.6 \\
\hline & fragments & 10.3 & 16.1 \\
\hline & NIap & 6.26 & 6.81 \\
\hline & NIml & 11.23 & 9.95 \\
\hline & NJ & 17.49 & 16.76 \\
\hline
\end{tabular}

Appendix A2. Factor scores for individual specimens of Homo sapiens included in the principal components analysis presented in Table 8. SPECIMEN = individual cadaver. BONENUMB: $1=$ femur, $2=$ tibia, $3=$ humerus, $4=$ radius, $5=$ ulna. AGE $=$ chronological age in years. SEX: 1 = male, 2 = female. FAC1 - FAC3 indicate the factor scores for the individual section on the three derived principal components.

\begin{tabular}{|c|c|c|c|c|c|c|}
\hline SPECIMEN & BONENUMB & SEX & AGE & FAC1 & FAC2 & FAC3 \\
\hline \hline $82-14$ & 1.00 & 2.00 & 75.00 & -1.21936 & -0.00116 & -0.56710 \\
\hline
\end{tabular}


(Appendix A2) contd....

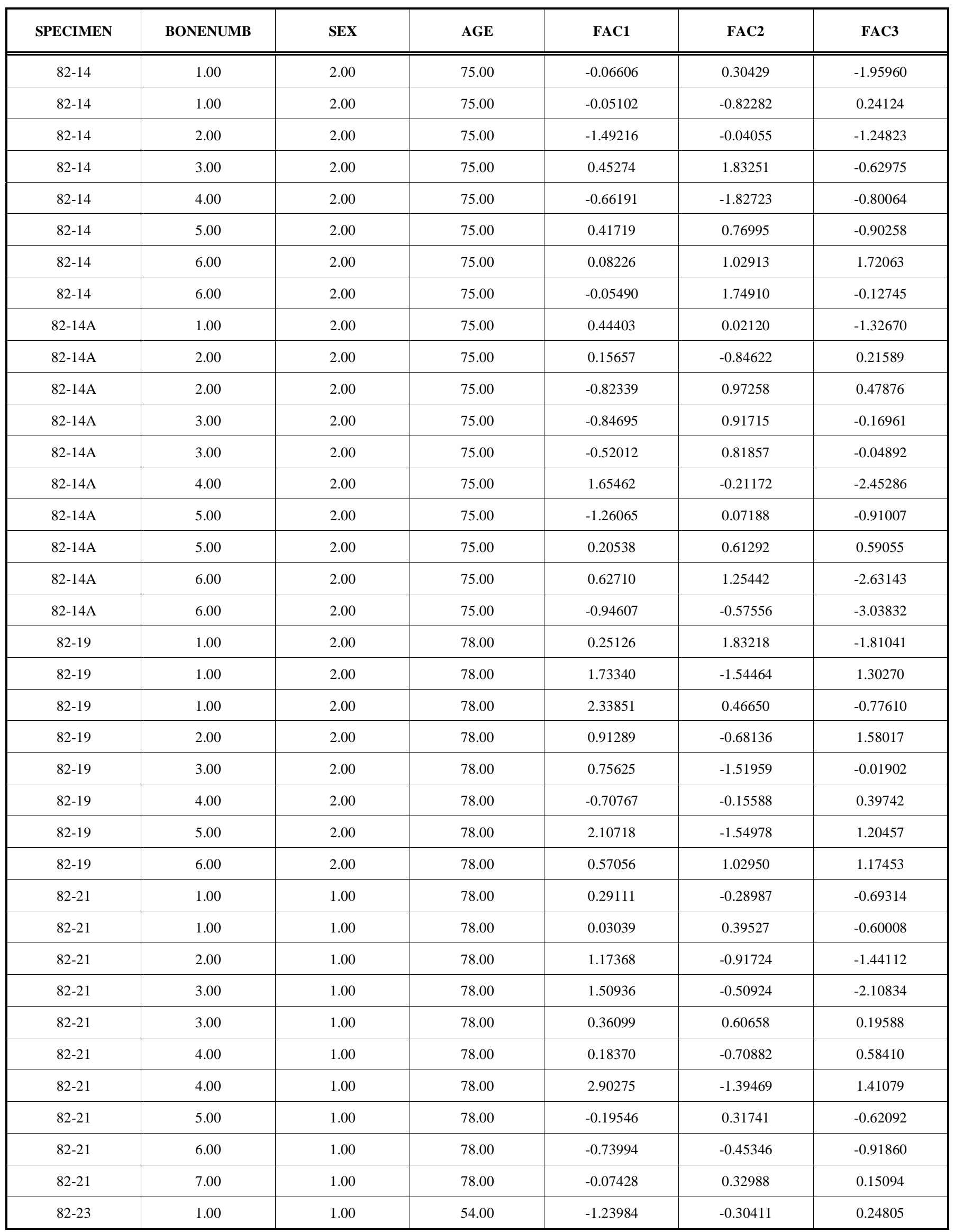


(Appendix A2) contd....

\begin{tabular}{|c|c|c|c|c|c|c|}
\hline SPECIMEN & BONENUMB & SEX & AGE & FAC1 & FAC2 & FAC3 \\
\hline $82-23$ & 2.00 & 1.00 & 54.00 & 0.05778 & 2.12390 & 0.70944 \\
\hline $82-23$ & 3.00 & 1.00 & 54.00 & -1.81223 & 1.58868 & 0.77772 \\
\hline $82-23$ & 3.00 & 1.00 & 54.00 & -1.13772 & 0.40975 & -0.97405 \\
\hline $82-23$ & 4.00 & 1.00 & 54.00 & -2.09845 & 0.85770 & -0.37012 \\
\hline $82-23$ & 5.00 & 1.00 & 54.00 & -0.85811 & 1.42546 & 1.13198 \\
\hline $82-23$ & 6.00 & 1.00 & 54.00 & -1.79119 & 2.32985 & 0.05595 \\
\hline $82-24$ & 1.00 & 2.00 & 79.00 & -0.05598 & -0.58911 & -2.13472 \\
\hline $82-24$ & 1.00 & 2.00 & 79.00 & 0.72851 & 0.05896 & -1.23471 \\
\hline $82-24$ & 3.00 & 2.00 & 79.00 & 0.51417 & 0.64619 & -0.49470 \\
\hline $82-24$ & 4.00 & 2.00 & 72.00 & 2.82167 & 0.23498 & -3.79683 \\
\hline $82-24$ & 4.00 & 2.00 & 72.00 & 1.93796 & -0.43047 & -2.11429 \\
\hline $82-24$ & 4.00 & 2.00 & 79.00 & -0.46255 & 0.03091 & -0.43953 \\
\hline $82-24$ & 5.00 & 2.00 & 72.00 & -0.71666 & 0.62245 & -0.05494 \\
\hline $82-24$ & 5.00 & 2.00 & 79.00 & 0.76262 & 1.38214 & -0.90875 \\
\hline $82-24$ & 6.00 & 2.00 & 72.00 & -1.03493 & 2.15428 & 0.13890 \\
\hline $82-31$ & 1.00 & 1.00 & 65.00 & -0.92607 & -1.44813 & -0.77693 \\
\hline $82-31$ & 1.00 & 1.00 & 65.00 & 0.81936 & -1.47316 & -1.43513 \\
\hline $82-31$ & 2.00 & 1.00 & 65.00 & -0.74992 & -1.05039 & 0.75566 \\
\hline $82-31$ & 2.00 & 1.00 & 65.00 & -0.61406 & -0.28355 & -1.31640 \\
\hline $82-31$ & 2.00 & 1.00 & 65.00 & -0.87197 & -0.61640 & -0.52769 \\
\hline $82-31$ & 4.00 & 1.00 & 65.00 & -0.49771 & -1.16678 & -0.43807 \\
\hline $82-31$ & 5.00 & 1.00 & 65.00 & -1.02642 & -0.23814 & 0.24949 \\
\hline $82-31$ & 6.00 & 1.00 & 65.00 & -0.89403 & -0.27039 & -0.78685 \\
\hline $83-05$ & 1.00 & 2.00 & 73.00 & -1.36850 & 0.25220 & -1.01842 \\
\hline $83-05$ & 1.00 & 2.00 & 73.00 & 0.92061 & 0.02056 & 0.52970 \\
\hline 83-05 & 2.00 & 2.00 & 73.00 & 0.41317 & -0.04979 & 0.12803 \\
\hline 83-05 & 2.00 & 2.00 & 73.00 & -1.68761 & 0.40151 & -1.42023 \\
\hline 83-05 & 3.00 & 2.00 & 73.00 & -0.86563 & 2.16965 & -1.13959 \\
\hline $83-05$ & 3.00 & 2.00 & 73.00 & 0.70558 & 0.37279 & -0.89721 \\
\hline 83-05 & 4.00 & 2.00 & 73.00 & -0.45164 & -0.35858 & 0.09763 \\
\hline $83-05$ & 5.00 & 2.00 & 73.00 & -0.94183 & -1.82235 & 0.33189 \\
\hline 83-05 & 6.00 & 2.00 & 73.00 & 1.09209 & 0.93008 & 0.95479 \\
\hline $83-05$ & 7.00 & 2.00 & 73.00 & -0.66733 & 0.00204 & -0.11907 \\
\hline 83-11 & 1.00 & 2.00 & 69.00 & 1.59208 & 0.35182 & -2.41868 \\
\hline 83-11 & 1.00 & 2.00 & 69.00 & 1.59208 & 0.35182 & -2.41868 \\
\hline 83-11 & 1.00 & 2.00 & 69.00 & 2.01797 & 0.57049 & -2.09642 \\
\hline 83-11 & 2.00 & 2.00 & 69.00 & 1.98690 & 0.37795 & 0.23932 \\
\hline
\end{tabular}




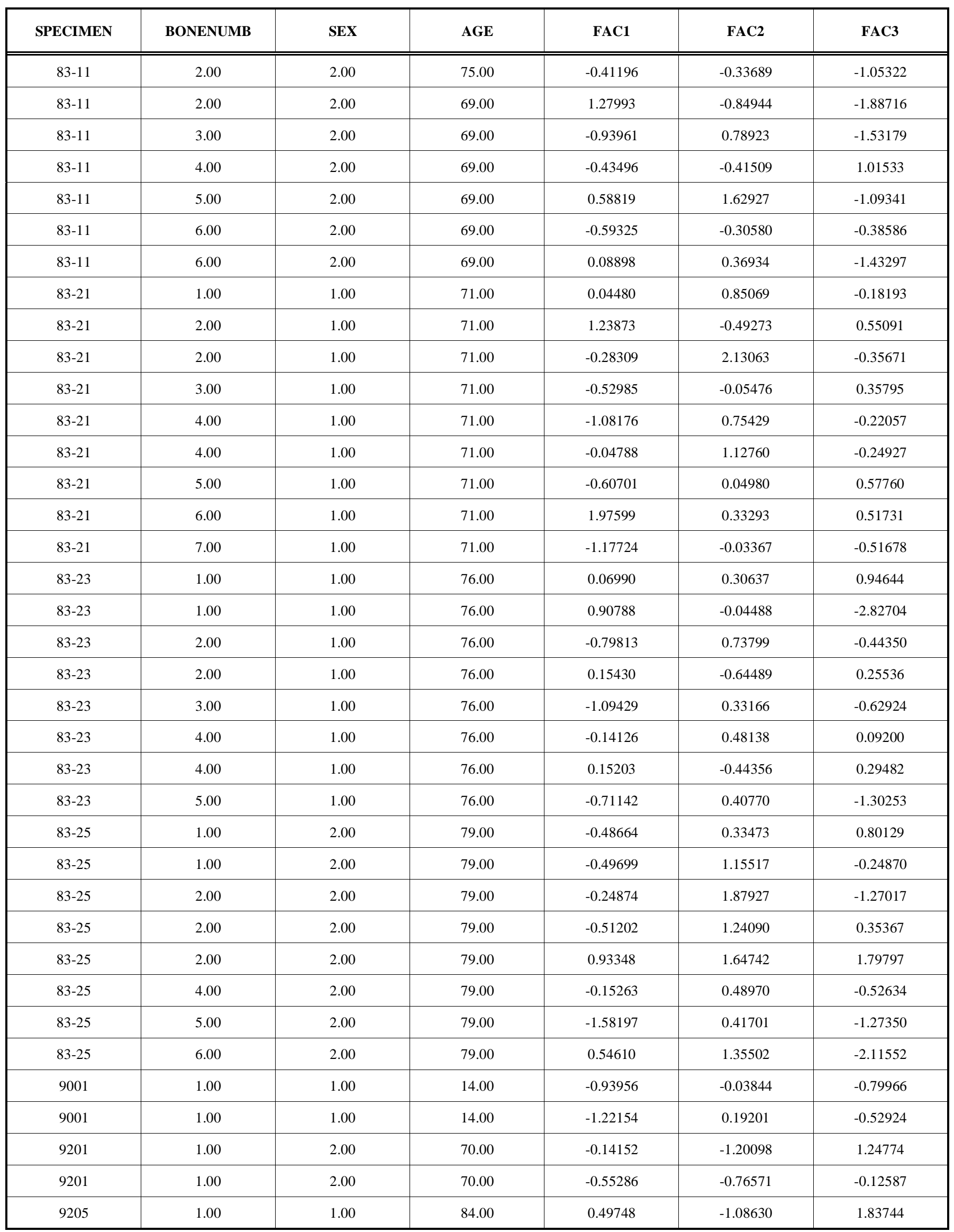


(Appendix A2) contd....

\begin{tabular}{|c|c|c|c|c|c|c|}
\hline SPECIMEN & BONENUMB & SEX & AGE & FAC1 & FAC2 & FAC3 \\
\hline 9205 & 1.00 & 1.00 & 84.00 & 0.28935 & -0.98100 & -0.23693 \\
\hline 9207 & 1.00 & 2.00 & 69.00 & 1.42481 & -0.63638 & 0.77325 \\
\hline 9207 & 1.00 & 2.00 & 69.00 & 0.35056 & 0.55854 & 0.47390 \\
\hline 9208 & 1.00 & 2.00 & 64.00 & -0.74952 & -0.93835 & -0.12710 \\
\hline 9208 & 1.00 & 2.00 & 64.00 & 0.94783 & -1.52199 & 0.84531 \\
\hline 9208 & 2.00 & 2.00 & 64.00 & -0.24258 & -0.13176 & 0.42947 \\
\hline 9208 & 2.00 & 2.00 & 64.00 & 0.94783 & -1.79741 & 0.48478 \\
\hline 9208 & 3.00 & 2.00 & 64.00 & -0.55220 & -0.14069 & -0.29522 \\
\hline 9208 & 4.00 & 2.00 & 64.00 & -0.39790 & -1.37062 & -0.04327 \\
\hline 9208 & 5.00 & 2.00 & 64.00 & 0.25118 & -1.51800 & 0.20241 \\
\hline 9208 & 6.00 & 2.00 & 64.00 & 0.26518 & -0.83029 & 0.36676 \\
\hline 9208 & 7.00 & 2.00 & 64.00 & -0.54543 & -1.39228 & 0.96110 \\
\hline 9210 & 1.00 & 1.00 & 83.00 & 0.84934 & -0.72083 & -0.02612 \\
\hline 9210 & 1.00 & 1.00 & 83.00 & -0.98117 & -0.64597 & 0.22476 \\
\hline 9210 & 1.00 & 1.00 & 83.00 & 0.26382 & 0.42308 & 0.32746 \\
\hline 9210 & 2.00 & 1.00 & 83.00 & -0.09646 & 0.04659 & 0.66560 \\
\hline 9210 & 2.00 & 1.00 & 83.00 & 0.53934 & 0.67425 & 0.45239 \\
\hline 9210 & 2.00 & 1.00 & 83.00 & -1.09084 & -1.06323 & 0.28997 \\
\hline 9210 & 3.00 & 1.00 & 83.00 & -0.38353 & -0.07199 & 0.55303 \\
\hline 9210 & 4.00 & 1.00 & 83.00 & 0.37502 & -0.63642 & -0.04777 \\
\hline 9210 & 6.00 & 1.00 & 83.00 & -0.12380 & -0.07782 & 0.29986 \\
\hline 9210 & 7.00 & 1.00 & 83.00 & -0.82159 & -1.01260 & 0.06166 \\
\hline 9211 & 1.00 & 2.00 & 95.00 & -0.48615 & -0.29008 & -0.23709 \\
\hline 9211 & 2.00 & 2.00 & 95.00 & 1.13091 & -0.14513 & 1.38493 \\
\hline 9211 & 5.00 & 2.00 & 95.00 & -0.24022 & -1.16876 & -0.08881 \\
\hline 9216 & 1.00 & 1.00 & 71.00 & -0.43496 & -0.41509 & 1.01533 \\
\hline 9216 & 1.00 & 1.00 & 71.00 & 0.40656 & -0.72867 & -0.32676 \\
\hline 9216 & 2.00 & 1.00 & 71.00 & 0.30945 & 1.03152 & 0.82035 \\
\hline 9216 & 2.00 & 1.00 & 71.00 & 1.67915 & 0.56210 & 0.16263 \\
\hline 9216 & 3.00 & 1.00 & 71.00 & 0.46763 & 0.51302 & -0.88839 \\
\hline 9216 & 4.00 & 1.00 & 71.00 & 0.45948 & -0.42972 & 1.01760 \\
\hline 9216 & 5.00 & 1.00 & 71.00 & -0.64850 & 0.49555 & 0.91779 \\
\hline 9216 & 6.00 & 1.00 & 71.00 & -0.53929 & -0.47481 & 0.55869 \\
\hline 9216 & 7.00 & 1.00 & 71.00 & -0.12210 & -1.03976 & 0.70353 \\
\hline 9219 & 1.00 & 1.00 & 73.00 & -1.29672 & -0.48260 & -1.07623 \\
\hline 9219 & 2.00 & 1.00 & 73.00 & -1.72100 & 0.76165 & -1.69179 \\
\hline 9219 & 2.00 & 1.00 & 73.00 & -1.05553 & -0.35966 & -0.11805 \\
\hline
\end{tabular}


(Appendix A2) contd....

\begin{tabular}{|c|c|c|c|c|c|c|}
\hline 9219 & 3.00 & 1.00 & 73.00 & 1.49274 & 1.20421 & 0.34751 \\
\hline 9219 & 4.00 & 1.00 & 73.00 & -0.38353 & 0.12270 & -0.01049 \\
\hline 9219 & 5.00 & 1.00 & 73.00 & -1.33533 & 0.70655 & -0.27270 \\
\hline 9220 & 1.00 & 1.00 & 72.00 & -0.50884 & -1.34852 & 0.41540 \\
\hline 9220 & 1.00 & 1.00 & 72.00 & 0.21319 & -1.42040 & 0.47376 \\
\hline 9220 & 2.00 & 1.00 & 72.00 & -0.07998 & -1.07228 & 0.75386 \\
\hline 9220 & 4.00 & 1.00 & 72.00 & -0.20466 & -1.61685 & 0.16711 \\
\hline 9220 & 5.00 & 1.00 & 72.00 & -0.39091 & -0.11430 & 0.23172 \\
\hline 9220 & 6.00 & 1.00 & 72.00 & -0.63877 & -1.50256 & -0.09594 \\
\hline 9220 & 7.00 & 1.00 & 72.00 & -0.12078 & -0.69699 & -0.43156 \\
\hline 9221 & 2.00 & 2.00 & 67.00 & 2.35010 & -2.03029 & 1.13059 \\
\hline 9221 & 2.00 & 2.00 & 67.00 & -0.06926 & -1.97128 & 0.88075 \\
\hline 9221 & 3.00 & 2.00 & 67.00 & -0.88070 & -1.25036 & -0.06886 \\
\hline 9222 & 1.00 & 1.00 & 73.00 & -1.09709 & -0.32758 & -0.16771 \\
\hline 9222 & 2.00 & 1.00 & 73.00 & -0.12590 & -1.09533 & 0.38429 \\
\hline 9222 & 2.00 & 1.00 & 73.00 & -0.66828 & -1.35364 & 0.50011 \\
\hline 9222 & 3.00 & 1.00 & 73.00 & -0.43838 & -0.72057 & -0.26320 \\
\hline 9222 & 3.00 & 1.00 & 73.00 & -0.35259 & -0.70523 & -0.36112 \\
\hline 9222 & 4.00 & 1.00 & 73.00 & -0.37067 & -0.03288 & 0.27642 \\
\hline 9222 & 4.00 & 1.00 & 73.00 & 0.50501 & -0.66167 & 1.03041 \\
\hline 9222 & 5.00 & 1.00 & 73.00 & -0.47410 & -0.24419 & 0.09131 \\
\hline 9222 & 6.00 & 1.00 & 73.00 & -0.40674 & -0.58736 & 0.11026 \\
\hline 9401 & 1.00 & 2.00 & 90.00 & -0.70058 & -0.08469 & -0.78722 \\
\hline 9401 & 1.00 & 2.00 & 90.00 & -0.75208 & 0.66875 & 0.81372 \\
\hline 9401 & 2.00 & 2.00 & 90.00 & -0.19989 & -0.16473 & 0.48049 \\
\hline 9401 & 2.00 & 2.00 & 90.00 & -0.53005 & 0.96366 & 0.27059 \\
\hline 9401 & 2.00 & 2.00 & 90.00 & -0.96447 & -0.38943 & -0.30301 \\
\hline
\end{tabular}


(Appendix A2) contd....

\begin{tabular}{|c|c|c|c|c|c|c|}
\hline SPECIMEN & BONENUMB & SEX & AGE & FAC1 & FAC2 & FAC3 \\
\hline 9401 & 3.00 & 2.00 & 90.00 & -1.18779 & 1.08650 & 1.21728 \\
\hline 9401 & 4.00 & 2.00 & 90.00 & 0.13612 & 0.96575 & 0.57107 \\
\hline 9401 & 5.00 & 2.00 & 90.00 & -1.34389 & -0.67633 & 0.63273 \\
\hline 9401 & 6.00 & 2.00 & 90.00 & -1.02043 & 0.18004 & 0.04368 \\
\hline 9401 & 6.00 & 2.00 & 90.00 & -1.08421 & 0.12782 & 0.55068 \\
\hline 9401 & 7.00 & 2.00 & 90.00 & -0.91331 & -0.18606 & 0.11178 \\
\hline 9402 & 1.00 & 1.00 & 71.00 & 0.60028 & 0.18807 & 1.64171 \\
\hline 9402 & 1.00 & 1.00 & 71.00 & -0.18636 & -0.89440 & 0.64697 \\
\hline 9402 & 2.00 & 1.00 & 71.00 & 0.77922 & -0.74311 & 0.47861 \\
\hline 9402 & 2.00 & 1.00 & 71.00 & -0.35048 & -1.15067 & 0.36994 \\
\hline 9402 & 3.00 & 1.00 & 71.00 & 0.59371 & -0.12931 & -0.85292 \\
\hline 9402 & 4.00 & 1.00 & 71.00 & 0.01801 & -0.72117 & 0.65881 \\
\hline 9402 & 4.00 & 1.00 & 71.00 & -0.62982 & -0.86798 & -0.55433 \\
\hline 9402 & 5.00 & 1.00 & 71.00 & -0.02935 & -0.14317 & -2.30665 \\
\hline 9402 & 6.00 & 1.00 & 71.00 & -0.54032 & -0.67674 & -0.99702 \\
\hline 9402 & 7.00 & 1.00 & 71.00 & -1.78946 & -0.19835 & -0.17368 \\
\hline 9403 & 1.00 & 2.00 & 83.00 & 3.77620 & 2.05571 & 1.20988 \\
\hline 9403 & 1.00 & 2.00 & 83.00 & 0.80015 & -0.64561 & 1.73695 \\
\hline 9403 & 2.00 & 2.00 & 83.00 & 0.56589 & 0.44654 & -1.67597 \\
\hline 9403 & 2.00 & 2.00 & 83.00 & 1.10632 & -0.33119 & 0.70756 \\
\hline 9403 & 3.00 & 2.00 & 83.00 & -0.26075 & -1.25132 & -0.13413 \\
\hline 9403 & 4.00 & 2.00 & 83.00 & 0.86376 & 0.06112 & 1.06571 \\
\hline 9403 & 5.00 & 2.00 & 83.00 & -0.08601 & -0.55916 & -0.05287 \\
\hline 9403 & 6.00 & 2.00 & 83.00 & -0.22455 & 0.14548 & 0.51256 \\
\hline 9403 & 7.00 & 2.00 & 83.00 & 0.13741 & 1.10071 & 2.11298 \\
\hline 9405 & 1.00 & 2.00 & 84.00 & 0.77024 & 2.03620 & 1.05380 \\
\hline 9405 & 1.00 & 2.00 & 84.00 & 1.84207 & 0.59066 & -0.51707 \\
\hline 9405 & 2.00 & 2.00 & 84.00 & 2.94190 & -0.46527 & -2.57223 \\
\hline 9405 & 2.00 & 2.00 & 84.00 & -0.20519 & -0.80457 & -0.87125 \\
\hline 9405 & 3.00 & 2.00 & 84.00 & 0.04712 & -0.01296 & 0.54568 \\
\hline 9405 & 4.00 & 2.00 & 84.00 & 1.82006 & -0.29316 & -0.12909 \\
\hline 9405 & 5.00 & 2.00 & 84.00 & 2.07313 & 1.45352 & 1.49072 \\
\hline 9405 & 7.00 & 2.00 & 84.00 & -0.59186 & 0.94387 & 1.39178 \\
\hline 9501 & 1.00 & 2.00 & 101.00 & 3.81662 & -0.76309 & -0.54027 \\
\hline 9501 & 2.00 & 2.00 & 101.00 & 0.05041 & -0.22187 & -0.09866 \\
\hline 9501 & 2.00 & 2.00 & 101.00 & 0.56565 & -0.46353 & 0.85232 \\
\hline 9501 & 4.00 & 2.00 & 101.00 & -0.09356 & -0.54498 & 1.75384 \\
\hline
\end{tabular}


(Appendix A2) contd....

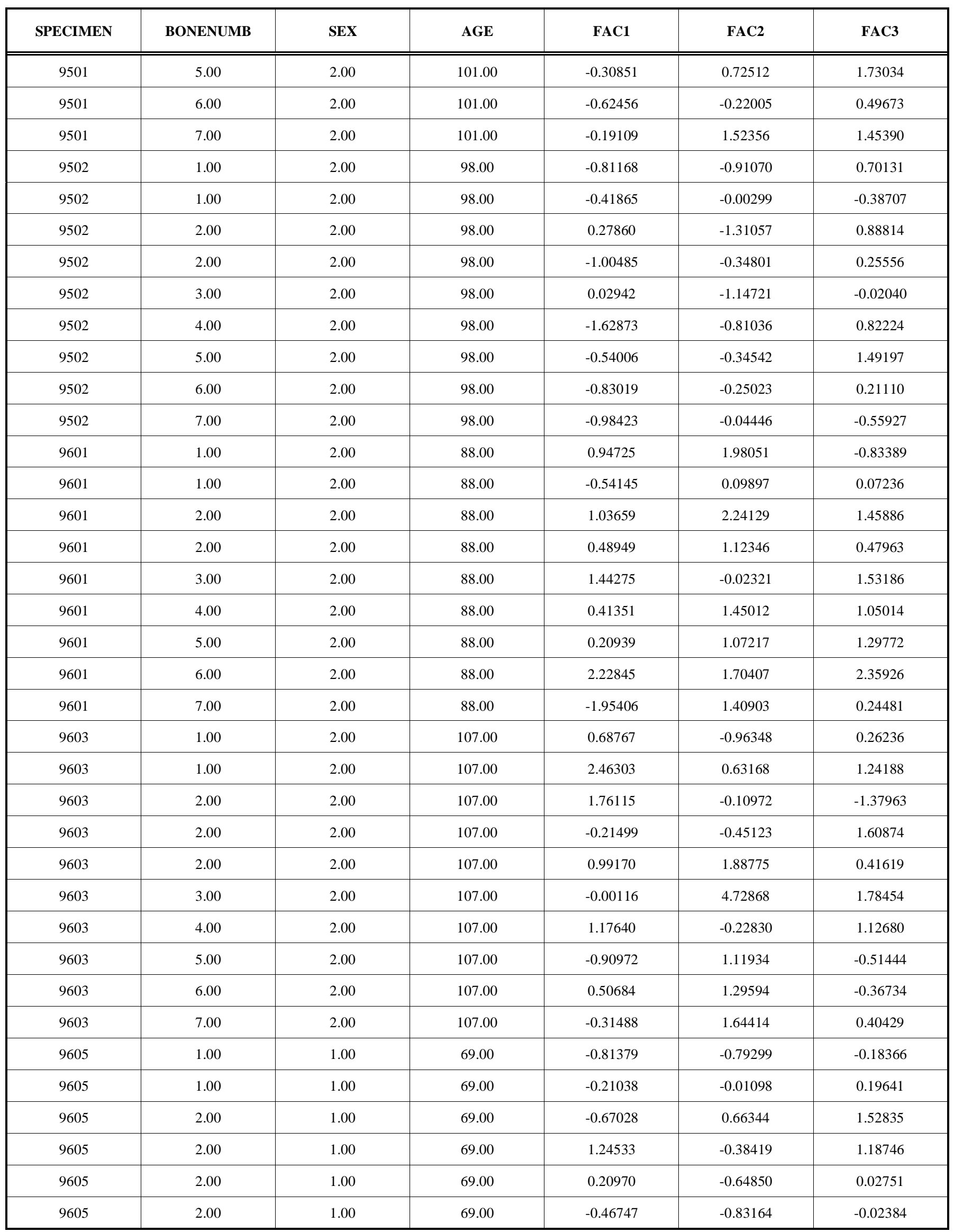


(Appendix A2) contd....

\begin{tabular}{|c|c|c|c|c|c|c|}
\hline 9605 & 3.00 & 1.00 & 69.00 & -1.19727 & -0.52100 & 0.26002 \\
\hline 9605 & 4.00 & 1.00 & 69.00 & 0.39232 & 0.53261 & -0.07953 \\
\hline 9605 & 5.00 & 1.00 & 69.00 & -1.54447 & 0.02309 & -0.09651 \\
\hline 9605 & 7.00 & 1.00 & 69.00 & 1.70548 & 2.91099 & -2.02615 \\
\hline 9605 & 7.00 & 1.00 & 69.00 & -1.79454 & -0.59747 & 0.03740 \\
\hline 9606 & 1.00 & 1.00 & 67.00 & -0.99970 & 0.88243 & -0.08205 \\
\hline 9606 & 2.00 & 1.00 & 67.00 & -0.08539 & 0.58884 & -0.71640 \\
\hline 9606 & 2.00 & 1.00 & 67.00 & 0.50549 & -0.91602 & 0.67498 \\
\hline 9606 & 2.00 & 2.00 & 95.00 & -0.16435 & 0.59899 & 0.08550 \\
\hline 9606 & 3.00 & 2.00 & 95.00 & 0.41850 & 0.40487 & 0.53369 \\
\hline 9606 & 4.00 & 2.00 & 95.00 & 0.69755 & 1.10036 & 1.05963 \\
\hline 9606 & 5.00 & 1.00 & 67.00 & -0.41664 & 0.07744 & -0.97200 \\
\hline 9606 & 5.00 & 2.00 & 95.00 & -1.26552 & 0.75965 & 0.74031 \\
\hline 9704 & 4.00 & 1.00 & 64.00 & -0.31645 & -1.96938 & 0.54545 \\
\hline 9704 & 5.00 & 1.00 & 64.00 & -0.62671 & -0.02946 & 0.53409 \\
\hline 9704 & 6.00 & 1.00 & 64.00 & -0.92953 & -1.00561 & -1.29276 \\
\hline 9704 & 7.00 & 1.00 & 64.00 & 0.77595 & -0.34694 & -0.04676 \\
\hline
\end{tabular}

Appendix A3. Factor scores for individual specimens included in the principal components analysis presented in Table 9. KEY TO THE SPECIMEN NUMBERS: In the specimen number, Cat indicates that this is a section from Felis silvestris catus. Chk or $\mathrm{Ch}$ indicates that this is a section from Gallus gallus. $\mathrm{LF}, \mathrm{RF}=$ left and right femur. $\mathrm{LT}, \mathrm{RT}=$ left and right tibia. $\mathrm{LH}, \mathrm{RH}=$ left and right humerus. LR, RR = left and right radius. LU, RU = left and right ulna. LFUR, RFUR = left and right furcula. Numerals 1 through 9 indicate that the section is taken at 10\% through $90 \%$ of the bone's length from it's proximal end. All human specimens are taken at the 50\% section of the left and right ulnae. The specimen numbers of the human sections indicate cadaver number and whether the section is taken from the left or right ulna. FAC1 - FAC7 indicate the factor scores for the individual section on the seven derived principal components.

\begin{tabular}{|c|c|c|c|c|c|c|c|}
\hline SPECIMEN & FAC1 & FAC2 & FAC3 & FAC4 & FAC5 & FAC6 & FAC7 \\
\hline \hline LF 1 Cat & 0.22126 & -0.02795 & -0.50988 & -0.43255 & -1.06059 & -0.19360 & -1.78937 \\
\hline LF 2 Cat & -0.18144 & -0.05558 & -0.52305 & 0.13460 & 0.15994 & 0.03734 & -0.37493 \\
\hline
\end{tabular}


(Appendix A3) contd....

\begin{tabular}{|c|c|c|c|c|c|c|c|}
\hline LF 3 Cat & -0.56335 & 0.34162 & 0.34146 & 1.44755 & -1.82026 & 0.01171 & 0.10837 \\
\hline LF 5 Cat & -0.48799 & -0.06994 & -0.19533 & 0.61339 & -0.70789 & 0.03687 & 0.07511 \\
\hline LF 6 Cat & -0.46454 & -0.06969 & -0.17169 & 0.44558 & -0.49338 & 0.03802 & 0.11804 \\
\hline LF 8 Cat & -0.15162 & -0.30190 & -0.72302 & -0.19768 & -0.36603 & -0.03802 & -0.01793 \\
\hline LF 9 Cat & 0.40478 & -0.21332 & -1.11409 & -0.87584 & -0.00655 & -0.15668 & -0.38681 \\
\hline LT 1 Cat & 0.46368 & 0.17181 & -0.69795 & -0.38124 & -0.35761 & -0.15548 & -2.32739 \\
\hline LT 5 Cat & -0.53639 & 0.35681 & 0.24778 & 1.31826 & -0.85632 & 0.08532 & -0.33979 \\
\hline LT 6 Cat & -0.53971 & 0.16418 & 0.05976 & 1.13358 & -1.12562 & 0.05032 & 0.03227 \\
\hline LT 7 Cat & -0.52648 & -0.20236 & -0.30846 & 0.33040 & -0.02344 & 0.08023 & -0.06650 \\
\hline LT 8 Cat & -0.40224 & -0.50392 & -0.76718 & -0.19136 & 0.13000 & 0.04176 & 0.24261 \\
\hline LT 9 Cat & -0.27852 & -0.56438 & -1.01150 & -0.38120 & 0.40468 & 0.03840 & 0.21457 \\
\hline LH 1 Cat & 0.49508 & -0.12862 & -0.95963 & -0.89209 & -0.14817 & -0.19603 & -3.17194 \\
\hline LH 2 Cat & 0.07568 & -0.37774 & -0.90324 & -0.70144 & -0.23144 & -0.11130 & -0.98221 \\
\hline LH 8 Cat & -0.14796 & -0.19716 & -0.62101 & -0.09918 & -0.54551 & -0.03676 & 1.01551 \\
\hline LH 9 Cat & 0.74905 & 0.21346 & -0.76598 & -1.29833 & -0.76113 & -0.25170 & 4.13550 \\
\hline LR 1 Cat & -0.60235 & -0.36544 & -0.44512 & 0.21030 & 0.18618 & 0.10298 & 0.19541 \\
\hline LR 2 Cat & -0.68384 & -0.08252 & -0.12067 & 0.84180 & -0.28468 & 0.12383 & 0.31244 \\
\hline LR 3 Cat & -0.59122 & -0.19769 & -0.41153 & 0.54358 & 0.37521 & 0.15135 & 0.26317 \\
\hline LR 4 Cat & -0.61894 & -0.22769 & -0.34853 & 0.43625 & 0.35857 & 0.14113 & 0.24999 \\
\hline LR 5 Cat & -0.63209 & -0.40351 & -0.38215 & 0.01311 & 0.39025 & 0.10556 & 0.27051 \\
\hline LR 6 Cat & -0.61486 & -0.38339 & -0.50719 & 0.32259 & 0.05608 & 0.10518 & 0.31446 \\
\hline LR 7 Cat & -0.57191 & -0.53141 & -0.73794 & 0.11211 & 0.21339 & 0.09917 & 0.31073 \\
\hline LR 8 Cat & -0.55704 & -0.64866 & -0.88127 & -0.04493 & 0.26339 & 0.08964 & 0.30699 \\
\hline LR 9 Cat & -0.50023 & -0.66723 & -0.97046 & -0.13704 & 0.35170 & 0.08382 & 0.37108 \\
\hline LU 1 Cat & -0.46163 & -0.47193 & -0.73642 & 0.02258 & 0.24484 & 0.07274 & -0.35998 \\
\hline LU 2 Cat & -0.52342 & 0.19487 & 0.10812 & 0.85997 & -0.11451 & 0.10733 & -0.76670 \\
\hline LU 3 Cat & -0.61798 & 0.43027 & 0.15165 & 1.70602 & -0.19693 & 0.19637 & -0.29431 \\
\hline
\end{tabular}


(Appendix A3) contd....

\begin{tabular}{|c|c|c|c|c|c|c|c|}
\hline SPECIMEN & FAC1 & FAC2 & FAC3 & FAC4 & FAC5 & FAC6 & FAC7 \\
\hline LU 4 Cat & -0.58978 & 0.13274 & -0.19828 & 1.24367 & 0.10009 & 0.18527 & -0.07175 \\
\hline LU 5 Cat & -0.59922 & -0.20889 & -0.37553 & 0.53731 & 0.21556 & 0.13359 & 0.05265 \\
\hline LU 6 Cat & -0.66767 & -0.12652 & -0.18635 & 0.66391 & 0.14856 & 0.14405 & 0.12755 \\
\hline LU 7 Cat & -0.62290 & -0.34627 & -0.44385 & 0.30226 & 0.23832 & 0.11821 & 0.19144 \\
\hline LU 8 Cat & -0.56063 & -0.65937 & -0.91335 & -0.01224 & 0.26818 & 0.09356 & 0.25783 \\
\hline LU 9 Cat & -0.52409 & -0.80421 & -1.13410 & -0.24261 & 0.55422 & 0.09590 & 0.14703 \\
\hline RF 1 Cat & 0.06223 & -0.08904 & -0.46117 & -0.30558 & -0.87938 & -0.15160 & -1.81237 \\
\hline RF 2 Cat & -0.30988 & -0.18641 & -0.54704 & 0.08175 & 0.33208 & 0.06568 & -0.18328 \\
\hline RF 3 Cat & -0.39490 & -0.39318 & -0.65490 & -0.00549 & -0.06435 & 0.03550 & 0.06228 \\
\hline RF 4 Cat & -0.33323 & -0.40565 & -0.77252 & 0.01996 & -0.16294 & 0.02275 & -0.04133 \\
\hline RF 5 Cat & -0.32862 & -0.50001 & -0.97667 & -0.11720 & 0.43767 & 0.07092 & 0.07885 \\
\hline RF 6 Cat & -0.44827 & 0.01652 & -0.16778 & 0.63232 & -0.46771 & 0.05614 & 0.13324 \\
\hline RF 7 Cat & -0.39194 & -0.36394 & -0.62003 & -0.02374 & 0.03473 & 0.04326 & 0.16458 \\
\hline RF 8 Cat & -0.33100 & -0.54727 & -0.84326 & -0.37241 & 0.14698 & 0.01506 & 0.02709 \\
\hline RF 9 Cat & 0.06866 & -0.49688 & -1.06905 & -0.93781 & 0.13234 & -0.09217 & 0.06061 \\
\hline RT 1 Cat & 0.44315 & 0.10383 & -0.60310 & -0.51043 & -0.75538 & -0.21441 & -2.91642 \\
\hline RT 2 Cat & -0.24353 & 0.40016 & 0.09021 & 1.09261 & -1.34844 & -0.02272 & -0.89592 \\
\hline RT 3 Cat & -0.45476 & 0.20898 & 0.05017 & 0.92056 & -0.58115 & 0.06424 & -0.41559 \\
\hline RT 4 Cat & -0.46364 & 0.06551 & -0.14174 & 0.68418 & -0.06712 & 0.09714 & -0.28200 \\
\hline RT 5 Cat & -0.52867 & 0.06173 & -0.00198 & 0.59166 & 0.03645 & 0.10321 & -0.28115 \\
\hline RT 6 Cat & -0.46275 & -0.24998 & -0.44752 & 0.12231 & 0.36903 & 0.09373 & 0.05708 \\
\hline RT 7 Cat & -0.55844 & -0.08835 & -0.13447 & 0.50356 & -0.19190 & 0.08178 & 0.01617 \\
\hline RT 8 Cat & -0.42070 & -0.56147 & -0.84131 & -0.24084 & 0.34827 & 0.05962 & 0.12294 \\
\hline RT 9 Cat & -0.24601 & -0.60952 & -1.11341 & -0.41862 & 0.42806 & 0.03049 & -0.05210 \\
\hline RH 1 Cat & 0.25864 & -0.29952 & -0.95502 & -0.82105 & -0.15567 & -0.15179 & -2.16811 \\
\hline RH 2 Cat & 0.12545 & -0.25555 & -0.86898 & -0.54301 & -0.04571 & -0.09462 & -1.69484 \\
\hline RH 3 Cat & -0.24456 & 0.40836 & 0.22807 & 1.04191 & -1.88611 & -0.07941 & -0.71260 \\
\hline RH 4 Cat & -0.49892 & 0.30365 & 0.33382 & 1.13173 & -1.54745 & -0.00537 & -0.34911 \\
\hline RH 5 Cat & -0.57146 & 0.35207 & 0.42533 & 1.19502 & -1.17747 & 0.04430 & -0.17268 \\
\hline RH 6 Cat & -0.55140 & 0.06190 & -0.02514 & 0.96850 & -0.96983 & 0.05060 & 0.00159 \\
\hline RH 7 Cat & -0.58582 & 0.09971 & 0.07538 & 1.11087 & -1.37595 & 0.03058 & 0.20565 \\
\hline RH 8 Cat & -0.42650 & 0.28322 & 0.15102 & 1.17925 & -1.85689 & -0.02164 & 0.77750 \\
\hline RH 9 Cat & -0.43154 & 0.07334 & 0.01424 & 0.73475 & -1.23459 & -0.01760 & -0.57305 \\
\hline RR 1 Cat & -0.72397 & 0.42723 & 0.41186 & 1.57011 & -0.35207 & 0.18023 & 0.21085 \\
\hline RR 2 Cat & -0.77382 & 0.12512 & 0.39547 & 0.85068 & -0.31465 & 0.12135 & 0.28915 \\
\hline RR 3 Cat & -0.72943 & 0.29041 & 0.30202 & 1.31305 & -0.16178 & 0.17660 & 0.24119 \\
\hline RR 4 Cat & -0.69382 & 0.38958 & 0.26225 & 1.50922 & 0.03626 & 0.21059 & 0.20374 \\
\hline
\end{tabular}


(Appendix A3) contd....

\begin{tabular}{|c|c|c|c|c|c|c|c|}
\hline RR 5 Cat & -0.71622 & 0.03004 & 0.12544 & 0.82284 & -0.19058 & 0.12923 & 0.31972 \\
\hline RR 7 Cat & -0.78500 & 0.28648 & 0.35922 & 1.68204 & -1.29779 & 0.11300 & 0.41451 \\
\hline RR 8 Cat & -0.80444 & 0.33002 & 0.37015 & 1.99999 & -1.85849 & 0.09386 & 0.50716 \\
\hline RU 1 Cat & -0.55237 & 0.36621 & 0.63001 & 0.89751 & -1.06894 & 0.00505 & -1.21944 \\
\hline RU 2 Cat & -0.68870 & 0.67921 & 1.09055 & 1.28589 & -0.77615 & 0.08673 & -0.69724 \\
\hline RU 3 Cat & -0.78121 & 0.35795 & 0.80123 & 0.99605 & -0.60601 & 0.09621 & -0.15237 \\
\hline RU 7 Cat & -0.76946 & 0.20965 & 0.25456 & 1.61937 & -1.38283 & 0.09835 & 0.35793 \\
\hline RU 8 Cat & -0.82282 & 0.22669 & 0.37232 & 1.76120 & -1.89402 & 0.06927 & 0.50081 \\
\hline RU 9 Cat & -0.65423 & -0.37209 & -0.52799 & 0.70197 & -0.64044 & 0.08005 & 0.28715 \\
\hline LF $1 \mathrm{chk}$ & 1.40270 & 0.64994 & -0.53000 & -1.52032 & -2.19833 & -0.53957 & 1.08097 \\
\hline LF 2 chk & -0.13610 & -0.00457 & -0.21669 & 0.20697 & -1.41449 & -0.13670 & -1.20311 \\
\hline LF 3 chk & 0.19318 & 0.12753 & -0.20689 & -0.23964 & -1.52295 & -0.22967 & -1.94078 \\
\hline LF 4 chk & -0.22683 & 0.36753 & 0.67788 & -0.17338 & -1.01706 & -0.12140 & 0.29157 \\
\hline LT 1 chk & 0.50528 & -0.18244 & -0.96133 & -1.21321 & -0.60722 & -0.25680 & 0.83927 \\
\hline LT 2 chk & 0.02607 & -0.29262 & -0.62744 & -0.81051 & -0.27735 & -0.12760 & -0.17967 \\
\hline LT $3 \mathrm{chk}$ & -0.05286 & 0.16145 & -0.01894 & 0.16059 & -1.59736 & -0.15927 & -1.04012 \\
\hline LT 4 chk & -0.21864 & 0.28681 & 0.35408 & 0.40818 & -1.70578 & -0.13452 & -1.23430 \\
\hline LT 5 chk & -0.40992 & 0.30773 & 0.83792 & -0.07161 & -0.84538 & -0.08407 & -1.00944 \\
\hline LT 6 chk & -0.49329 & 0.78164 & 1.62117 & 0.37528 & -1.51029 & -0.10055 & -0.25890 \\
\hline LT 7 chk & -0.49967 & 0.72953 & 1.93004 & -0.65611 & -0.25041 & -0.08706 & 0.09288 \\
\hline LT 8 chk & 0.01889 & -0.05105 & -0.20177 & -0.75300 & -0.47928 & -0.14248 & 0.03749 \\
\hline LT 9 chk & 0.12683 & -0.19461 & -0.60747 & -0.80109 & -0.49974 & -0.15598 & 0.22232 \\
\hline LH 1 chk & 0.82638 & 0.83268 & -0.01590 & -0.36527 & -2.65842 & -0.38025 & 4.10975 \\
\hline LH 2 chk & 0.90504 & 0.94179 & 0.24049 & -0.65379 & -2.54355 & -0.40678 & 3.17359 \\
\hline LH 3 chk & -0.15059 & 0.02326 & 0.25363 & -1.02153 & 0.07836 & -0.09698 & 0.62759 \\
\hline LH 4 chk & -0.45574 & 0.14668 & 0.76515 & -0.65390 & 0.05191 & -0.03558 & 0.41840 \\
\hline LH 5 chk & -0.50738 & -0.10980 & 1.04047 & -2.27252 & 2.17096 & 0.00167 & -0.21972 \\
\hline
\end{tabular}


(Appendix A3) contd....

\begin{tabular}{|c|c|c|c|c|c|c|c|}
\hline SPECIMEN & FAC1 & FAC2 & FAC3 & FAC4 & FAC5 & FAC6 & FAC7 \\
\hline LH 6 chk & -0.71820 & 0.25406 & 1.54013 & -1.13120 & 0.95096 & 0.01372 & -0.00117 \\
\hline LH 7 chk & -0.36884 & -0.08095 & -0.04621 & 0.02192 & -0.73730 & -0.04464 & 0.32278 \\
\hline LH 8 chk & -0.14039 & 0.18140 & 0.11734 & -0.06822 & -1.13500 & -0.10807 & 1.27486 \\
\hline LH 9 chk & -0.21315 & -0.15889 & -0.21879 & -0.61734 & -0.15239 & -0.05456 & 1.66565 \\
\hline LR $1 \mathrm{chk}$ & -0.44218 & -0.93992 & -1.32711 & -0.54694 & 0.57776 & 0.06480 & 0.26974 \\
\hline LR $2 \mathrm{chk}$ & -0.58124 & -0.60792 & -0.79518 & 0.14114 & -0.21144 & 0.06361 & 0.32470 \\
\hline LR 3 chk & -0.70406 & -0.44416 & 0.00332 & -0.64456 & 0.79773 & 0.07839 & 0.18060 \\
\hline LR 4 chk & -1.26091 & 1.02113 & 3.63181 & -0.92070 & 1.09231 & 0.06991 & 0.03753 \\
\hline LR $5 \mathrm{chk}$ & -1.16576 & 0.79386 & 2.99222 & -0.72112 & 0.85004 & 0.06936 & 0.09211 \\
\hline LR 6 chk & -1.02018 & 0.47266 & 1.91944 & -0.06439 & 0.05268 & 0.06456 & 0.21738 \\
\hline LR $7 \mathrm{chk}$ & -0.97842 & 0.46298 & 1.62679 & 0.46445 & -0.62406 & 0.05431 & 0.30965 \\
\hline LR 8 chk & -0.61890 & -0.62659 & -0.46471 & -0.62689 & 0.75630 & 0.07736 & 0.23025 \\
\hline LR 9 chk & -0.50050 & -0.80115 & -1.11844 & -0.22867 & 0.21389 & 0.06233 & 0.33458 \\
\hline LU $1 \mathrm{chk}$ & -0.14586 & -0.30466 & -0.57765 & -0.50653 & -0.32299 & -0.07259 & 0.73039 \\
\hline LU 2 chk & -0.45623 & -0.11898 & 0.33364 & -0.82315 & 0.41925 & -0.01143 & 0.49029 \\
\hline LU 3 chk & -0.89309 & 0.68292 & 2.35143 & -0.57551 & 0.31821 & 0.01102 & 0.18223 \\
\hline LU 4 chk & -0.78855 & 0.41586 & 1.97963 & -1.25698 & 1.11617 & 0.01716 & 0.22186 \\
\hline LU 5 chk & -0.97054 & 0.73716 & 2.65476 & -0.75210 & 0.60012 & 0.02162 & -0.31429 \\
\hline LU 6 chk & -1.02636 & 0.83779 & 3.00922 & -0.97417 & 0.88696 & 0.02505 & -0.30390 \\
\hline LU 7 chk & -0.64770 & -0.07069 & 0.50147 & -0.28656 & 0.04895 & 0.02026 & -0.13270 \\
\hline LU 8 chk & -0.35792 & -0.70764 & -0.94972 & -0.59977 & 0.34328 & 0.00911 & -0.38779 \\
\hline LU 9 chk & -0.12590 & -0.78130 & -1.30026 & -0.83466 & 0.29408 & -0.05075 & -0.49177 \\
\hline RF 1 chk & 1.83424 & 0.39611 & -1.17038 & -2.79286 & -1.19571 & -0.59549 & 2.69733 \\
\hline RF 2 chk & 0.49241 & -0.44164 & -1.14032 & -1.49515 & -0.19349 & -0.25856 & -2.62052 \\
\hline RF 3 chk & -0.11341 & -0.13628 & -0.23947 & -0.50537 & -0.51956 & -0.11447 & -0.61636 \\
\hline RF 4 chk & -0.29126 & 0.10937 & 0.53760 & -0.70576 & -0.15095 & -0.08980 & -0.47839 \\
\hline RF 5 chk & -0.17697 & 0.13957 & 0.23001 & -0.16507 & -0.99243 & -0.12246 & -0.70886 \\
\hline RF 6 chk & 0.04035 & 0.48274 & 0.70243 & -0.49964 & -1.15883 & -0.20540 & -0.58187 \\
\hline RF 7 chk & 0.39479 & -0.05839 & -0.23428 & -1.87913 & 0.22506 & -0.24091 & -0.70038 \\
\hline RF 8 chk & 0.57390 & -0.11520 & -0.76924 & -1.58956 & -0.33053 & -0.26214 & 0.55068 \\
\hline RF 9 chk & 0.53164 & -0.34627 & -1.14971 & -1.45066 & -0.29656 & -0.25932 & -0.21897 \\
\hline RT 1 chk & 0.45949 & -0.48791 & -1.22648 & -1.38605 & -0.23508 & -0.25844 & -2.54028 \\
\hline RT 2 chk & 0.26186 & -0.42372 & -0.93241 & -1.27949 & -0.06834 & -0.18267 & -1.71549 \\
\hline RT 3 chk & 0.14618 & -0.37341 & -0.82437 & -1.03541 & -0.17583 & -0.14604 & -0.81510 \\
\hline RT 4 chk & -0.28580 & -0.23501 & -0.11043 & -0.77076 & 0.13715 & -0.04905 & -0.16585 \\
\hline RT 5 chk & -0.23683 & -0.10782 & 0.15150 & -0.96693 & 0.20143 & -0.07155 & -0.41599 \\
\hline RT 6 chk & -0.35700 & 0.11389 & 0.70834 & -0.97045 & 0.27282 & -0.05827 & 0.07033 \\
\hline
\end{tabular}


(Appendix A3) contd....

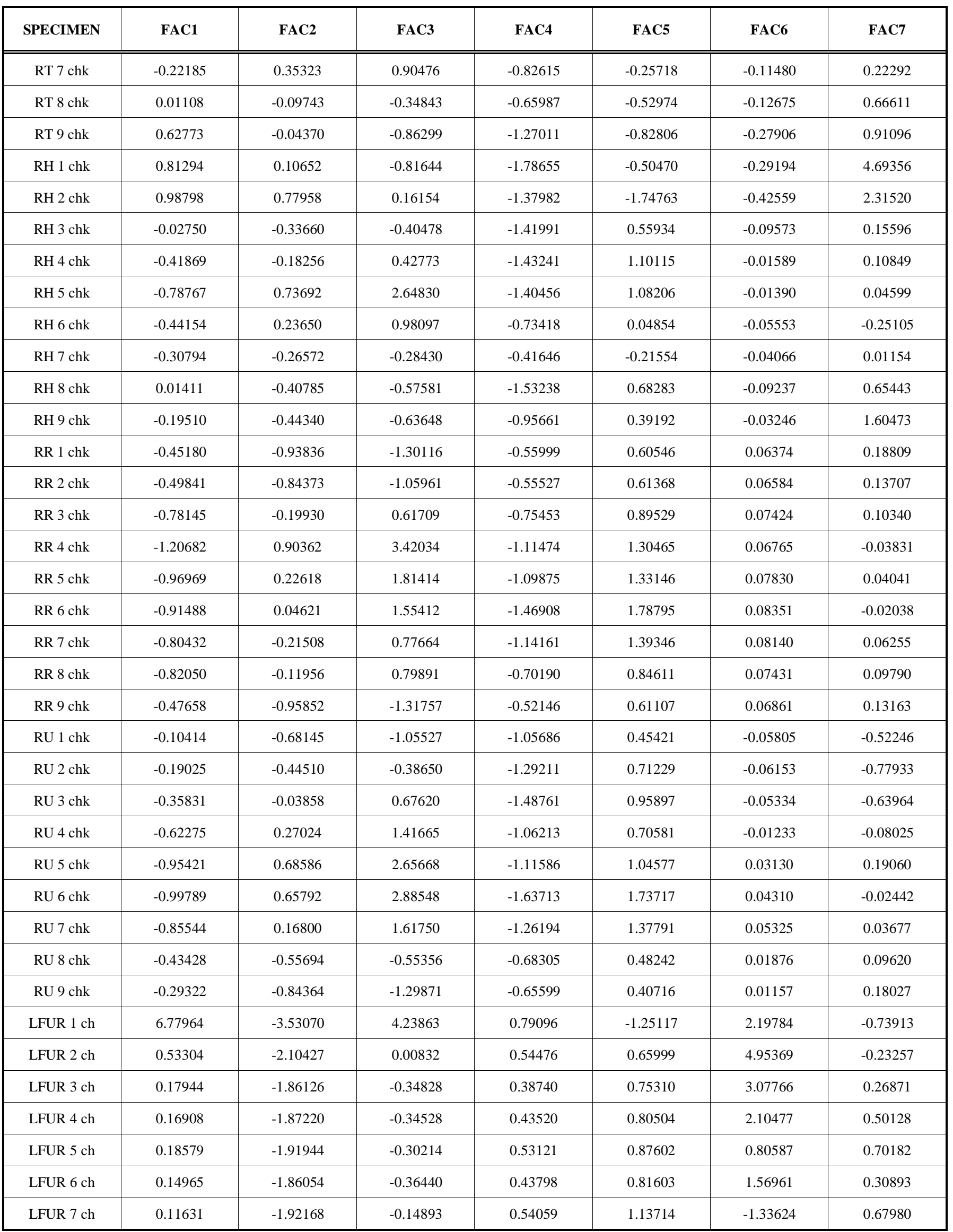


(Appendix A3) contd....

\begin{tabular}{|c|c|c|c|c|c|c|c|}
\hline SPECIMEN & FAC1 & FAC2 & FAC3 & FAC4 & FAC5 & FAC6 & FAC7 \\
\hline LFUR $8 \mathrm{ch}$ & 0.27034 & -2.32668 & 0.03852 & 1.19008 & 1.27474 & -4.65493 & 0.99601 \\
\hline LFUR $9 \mathrm{ch}$ & 1.89589 & -3.27929 & 1.60114 & 1.95263 & 1.11166 & -4.72989 & -0.02881 \\
\hline RFUR $1 \mathrm{ch}$ & 6.77964 & -3.53070 & 4.23863 & 0.79096 & -1.25117 & 2.19784 & -0.73913 \\
\hline RFUR $2 \mathrm{ch}$ & 0.78547 & -2.25981 & 0.25401 & 0.67034 & 0.66560 & 5.87926 & 1.13631 \\
\hline RFUR $3 \mathrm{ch}$ & 0.30503 & -1.97292 & -0.20172 & 0.50706 & 0.78588 & 2.95070 & 0.70500 \\
\hline RFUR $4 \mathrm{ch}$ & 0.19175 & -1.89898 & -0.31390 & 0.47474 & 0.82731 & 1.78473 & 0.64916 \\
\hline RFUR $5 \mathrm{ch}$ & 0.32655 & -2.02356 & -0.15428 & 0.60739 & 0.85276 & 1.50245 & 0.69063 \\
\hline RFUR $6 \mathrm{ch}$ & 0.16726 & -1.94009 & -0.28858 & 0.60401 & 0.92067 & -0.26148 & 0.63114 \\
\hline RFUR $7 \mathrm{ch}$ & 0.16934 & -2.03094 & -0.10327 & 0.71554 & 1.15695 & -2.21399 & 0.70527 \\
\hline RFUR $8 \mathrm{ch}$ & 0.67009 & -2.60656 & 0.44619 & 1.42973 & 1.24798 & -4.18536 & 0.99131 \\
\hline RFUR $9 \mathrm{ch}$ & 1.66618 & -3.39782 & 1.52597 & 2.24716 & 1.31942 & -7.14545 & -0.28651 \\
\hline $9711 \mathrm{left}$ & 1.26559 & 1.28854 & -0.33934 & -0.17651 & -0.11433 & -0.19807 & -0.49882 \\
\hline 9712 left & 0.33305 & 0.29419 & -1.08228 & 0.35437 & 1.10368 & 0.09547 & -0.30760 \\
\hline 9713 left & 1.03436 & 1.56552 & -0.63460 & 1.14753 & 1.81055 & 0.14776 & -0.37240 \\
\hline 9714 left & 0.21443 & 0.80893 & -0.32612 & 0.93565 & 0.92457 & 0.13989 & 0.14497 \\
\hline 9715 left & 2.98507 & 2.17480 & -0.05577 & -2.04063 & -1.93842 & -0.78922 & -3.21393 \\
\hline 9716 left & 2.95297 & 3.25288 & -0.46425 & 0.19607 & 1.92926 & -0.13483 & 2.77595 \\
\hline 9717 left & 1.31468 & 1.47138 & -0.22597 & -0.07162 & 0.04080 & -0.17260 & 0.20655 \\
\hline 9718 left & 1.41070 & 1.93997 & -0.65283 & 1.31552 & 1.56077 & 0.09371 & -0.60556 \\
\hline 9719 left & 0.78705 & 1.27915 & -0.38318 & 0.69432 & 1.09315 & 0.07600 & 1.06465 \\
\hline 9720 left & 0.43023 & 1.01856 & -0.41338 & 1.08873 & 1.19949 & 0.14640 & -0.89713 \\
\hline $9721 \mathrm{left}$ & 1.05168 & 1.38981 & -0.25113 & 0.43920 & 0.08465 & -0.08762 & 0.20218 \\
\hline 9722 left & 0.89899 & 1.58408 & -0.82940 & 1.77325 & 2.13640 & 0.26101 & -0.15276 \\
\hline $9723 \mathrm{left}$ & 1.64456 & 1.90867 & -0.42672 & 0.35075 & 0.48310 & -0.11069 & 1.84947 \\
\hline $9801 \mathrm{left}$ & 1.51816 & 1.73106 & -0.43554 & 0.27219 & 0.62192 & -0.10419 & 0.37565 \\
\hline 9711 right & 0.86823 & 1.03126 & -0.43128 & 0.17435 & 0.38459 & -0.06778 & -0.53169 \\
\hline 9712 right & 0.30559 & 0.40907 & -1.20506 & 0.76379 & 1.72890 & 0.20095 & -0.18783 \\
\hline 9713 right & 1.69912 & 2.39838 & -0.47310 & 1.36377 & 1.65795 & 0.08946 & 1.42597 \\
\hline 9714 right & 0.41255 & 1.23411 & 0.03745 & 1.17591 & 0.34762 & 0.07989 & 0.33750 \\
\hline 9715 right & 3.05459 & 1.75366 & -0.58278 & -2.79129 & -1.49815 & -0.80671 & -2.10003 \\
\hline 9716 right & 2.62325 & 2.87792 & -0.34974 & 0.15557 & 1.28182 & -0.17910 & 1.08621 \\
\hline 9717 right & 1.53739 & 1.87904 & -0.40693 & 0.38618 & 1.22432 & -0.03365 & 0.81889 \\
\hline 9718 right & 1.35078 & 1.89098 & -0.54825 & 1.12957 & 1.78241 & 0.09777 & -0.95556 \\
\hline 9719 right & 0.72367 & 1.42163 & -0.22838 & 1.06080 & 1.26543 & 0.12055 & -0.10247 \\
\hline 9720 right & 0.77021 & 1.65800 & -0.62610 & 2.03249 & 2.50789 & 0.31466 & -1.95346 \\
\hline 9721 right & 1.26272 & 1.48011 & -0.01822 & -0.08787 & -0.53467 & -0.22524 & 0.39027 \\
\hline 9722 right & 0.94851 & 2.14913 & -1.11640 & 3.20563 & 3.96942 & 0.56897 & -0.48304 \\
\hline
\end{tabular}


(Appendix A3) contd....

\begin{tabular}{|c|c|c|c|c|c|c|c|}
\hline SPECIMEN & FAC1 & FAC2 & FAC3 & FAC4 & FAC5 & FAC6 & FAC7 \\
\hline \hline 9723 right & 1.61019 & 1.72144 & -0.25225 & -0.21614 & 0.31932 & -0.19438 & 0.40706 \\
\hline 9801 right & 1.61313 & 2.28684 & -0.55273 & 1.53700 & 1.87497 & 0.11291 & -1.10403 \\
\hline
\end{tabular}

\section{REFERENCES}

[1] Karsenty G. Genetic control of skeletal development. The molecular basis of skeletogenesis. Novus Found Symp 2001; 232: 6-17.

[2] Karsenty G, Wagner EF. Reaching a genetic and molecular understanding of skeletal development. Dev Cell 2002; 2: 389-406.

[3] Shore EM, Xu M, Shah PB, et al. The human bone morphogenetic protein 4 (BMP-4) Gene: molecular structure and transcriptional regulation. Calcif Tissue Int 1998; 63: 221-9.

[4] Olsen BR, Reginato AM, Wang W. Bone development. Ann Rev Cell Dev Biol 2000; 16: 191-220

[5] Lovejoy CO, McCollum MA, Reno PL, Rosenman BA. Developmental biology and human evolution. An Rev Anthropol 2003; 32: 85-109.

[6] Biewener AA. Musculoskeletal design in relation to body size. J Biomech 1991; 24(Suppl 1): 19-29.

[7] Biewener AA. Safety factors in bone strength. Calcif Tissue Int 1993; 53(Suppl 1): S68-74.

[8] Biewener AA, Taylor CR. Bone strain: a determinant of gait and speed? J Exp Biol 1986; 123: 383-400.

[9] Burr DB, Milgrom C, Fyhie D, et al. In vivo measurement of human tibial strains during vigorous activity. Bone 1996; 18: 405-10.

[10] Fritton SP, McLeod KJ, Rubin CT. Quantifying the strain history of bone: spatial uniformity and self-similarity of flow-magnitude strains. J Biomech 2000; 33: 317-25.

[11] Currey J. Bones: structure and mechanics. Princeton, New Jersey, United States: Princeton University Press 2002.

[12] Wolff J. The law of bone remodeling (translated from the 1892 original, Das Gesetz der Transformation der Knochen, by P Maquet and R Furlong). Berlin, Germany: Springer Verlag 1986.

[13] Bertram JEA, Swartz SM. The 'law of bone transformation': a case of crying Wolff? Biol Rev 1991; 66: 245-73.

[14] Pearson OM, Leiberman DE. The aging of Wolff's "law": ontogeny and responses to mechanical loading in cortical bone. Yearb Phys Anthropol 2004; 47: 63-99.

[15] Walker RA. A survey of remodeling in the mammalian skeleton: a pilot study. Paper presented at the 67th Annual Meeting of the American Association of Physical Anthropologists, Salt Lake City, Utah, April 2, 1998. Am J Phys Anthropol 1998; (Suppl 26): 224-5.

[16] Walker RA, Lovejoy CO. A survey of remodeling in the vertebrate skeleton, part II. Paper presented at the 68th Annual Meeting of the American Association of Physical Anthropologists, Columbus, Ohio, April 29, 1999. Am J Phys Anthropol 1999; (Suppl 28): 272.

[17] Walker RA, Lovejoy CO, Meindl RS. The histomorphological and geometric properties of human femoral cortex in individuals over 50: implications for histomorphological determination of age-atdeath. Am J HumBiol 1994; 6: 659-67.

[18] Walker RA, Greiner TM. Bone histomorphometric correlates of biomechanics, limb use patterns, and bone function. Invited paper presented at the 2000 Annual Meeting of the American Association of Physical Anthropologists as a part of the "Current and Future Applications of Bone Histology to Biological Anthropology" symposium. Am J Phys Anthropol 2000; (Suppl 30): 313.

[19] Walker RA, Mitlansky N, Lovejoy CO. A survey of remodeling in the vertebrate skeleton, part III. variation in percentage haversian bone. Paper presented at the 2001 Annual Meeting of the American Association of Physical Anthropologists, Kansas City, Missouri, March 29, 2001. Am J Phys Anthropol 2001; (Suppl 32): 158.

[20] Walker RA, Lovejoy CO, Cordes R. Histomorphological variation in the human appendicular skeleton. Paper presented at the American Association of Physical Anthropologists Annual Meeting, Philadelphia, PA, March 29, 2007. Am J Phys Anthropol 2007; (Suppl 44): 241-2.

[21] Walker RA, Lovejoy CO, Cordes R. Remodeling variation in human skeletal elements. Paper presented at the American Associa- tion of Physical Anthropologists Annual Meeting, Columbus, Ohio, April 11, 2008. Am J Phys Anthropol 2008; (Suppl 46): 216

[22] Walker RA. Assessment of cortical bone dynamics and skeletal age at death from femoral cortical histomorphology. Ph.D. [dissertation], Kent (OH): School of Biomedical Sciences, Kent State University 1989.

[23] Stout SD, Dietze WA, Iscan MY, Loth SR. Estimation of age at death using cortical histomorphometry of the sternal end of the fourth rib. J Forensic Sci 1994; 39: 778-84.

[24] Stout SD, Lueck R. Bone remodeling rates and maturation in three archaeological skeletal populations. Am J Phys Anthropol 1995; 98: 161-71.

[25] Mulhern DM. Rib remodeling dynamics in a skeletal population from Kulubnarti, Nubia. Am J Phys Anthropol 2000; 111: 519-30.

[26] Cho H, Stout SD, Bishop TA. A comparison of cortical bone remodeling rates between African American and European American skeletal remains. Am J Phys Anthropol 2006; 130: 214-26.

[27] Walker FW Jr. A study of the cat with reference to human beings, $3^{\text {rd }}$ ed. Philadelphia, Pennsylvania, United States: W.B. Saunders Company 1977.

[28] Young WC. Roark's formulas for stress and strain, $6^{\text {th }}$ ed. New York, United States: McGraw-Hill 1989.

[29] Sheehan DC, Hrapchack BB. Theory and practice of histotechnology. St. Louis, Missouri, United States: C.V. Mosby Company 1980.

[30] Currey J. The mechanical adaptations of bone. Princeton, New Jersey, United States: Princeton University Press 1984.

[31] Cole J. Paw preference in cats related to hand preference in animals and man. J Comp Physiol Psychol 1955; 48: 137-40.

[32] Fagot J, Vauclair J. Manual laterality in nonhuman primates: a distinction between handedness and manual specialization. Psychol Bull1 1991; 109: 76-89.

[33] Pike AVL, Maitland DP. Paw preferences in cats (Felis silvestris catus) living in a household environment. Behav Processes 1997; 39: 241-7.

[34] Biddle FG, Coffaro CM, Ziehr JE, Eales BA. Genetic variation in paw preference (handedness) in the mouse. Genome 1993; 36: 93543.

[35] Heinonen A, Sievanen H, Kannus P, Oja P, Vuori I. Effects of unilateral strength training and detraining on bone mineral mass and estimated mechanical characteristics of the upper limb bones in young women. J Bone MinerRes1996; 11: 490-501.

[36] Frankel VH, Burstein AH. Orthopaedic biomechanics: the application of engineering to the musculoskeletal system. Philadelphia, Pennsylvania, United States: Lea and Febiger 1970.

[37] Walker RA, Mitlyansky N. Variation in remodeling about the perimeter of the midshaft human femur. Paper presented at the 2003 Annual Meeting of the American Association of Physical Anthropologists, Tempe, Arizona, April 26, 2003. Am J Phys Anthropol 2003; (Suppl 36): 218

[38] Cooley WW, Lohnes PR. Multivariate data analysis. New York, United States, John Wiley and Sons 1971.

[39] Happasalo H, Sievanen H, Kannus P, Heinonen A, Oja P, Vuori I. Dimensions and estimated mechanical characteristics of the humerus after long-term tennis loading. J Bone MinerRes 1996; 11: 86472 .

[40] Jones HH, Priest JD, Hayes WC, Chinn C, Nagel DA. Humeral hypertrophy in response to exercise. J Bone Jt Surg 1977; 59A: 204-8.

[41] Warshaw J. Comparative primate bone microstructure: records of life history, function, and phylogeny. In: Sargis EJ, Dagasto M, Eds. Mammalian evolutionary morphology: a tribute to Frederick S. Szalay. Dordrecht, The Netherlands 2008; pp. 385-426.

[42] Woo S, Kue SC, Amiel D, Gomez MA, Hayes WC. The effect of prolonged physical training on the properties of long bone: A study of Wolff's law. J Bone Jt Surg 1981; 63A: 780-7. 
[43] Walker RA. Properties of the cortex of the midshaft femur: variation in three human populations. Homo 2000; 51: 180-99.

[44] Frazer JE. The anatomy of the human skeleton, $2^{\text {nd }}$ ed. London, England, Churchill 1920.
[45] Reno PL, McCollum MA, Cohn MJ, Meindl RS, Hamrick M, Lovejoy CO. Patterns of correlation and covariation of anthropoid distal forelimb segments correspond to Hoxd expression territories. J Exp Zool B Mol Dev Evol 2008; 310: 240-258.

(C) Walker et al.; Licensee Bentham Open.

This is an open access article licensed under the terms of the Creative Commons Attribution Non-Commercial License (http://creativecommons.org/licenses/ by-nc/3.0/) which permits unrestricted, non-commercial use, distribution and reproduction in any medium, provided the work is properly cited. 